\title{
Projection in Future Drought Hazard of South Korea Based on RCP Climate Change Scenario 8.5 Using SPEI
}

\author{
Byung Sik Kim, ${ }^{1}$ In Gi Chang, ${ }^{1}$ Jang Hyun Sung, ${ }^{2}$ and Hae Jin Han ${ }^{3}$ \\ ${ }^{1}$ Department of Urban \& Environmental Disaster Prevention, School of Disaster Prevention, Kangwon National University, \\ 345 Jungang-ro, Samcheck-si, Gangwon-do, Republic of Korea \\ ${ }^{2}$ Ministry of Land, Infrastructure and Transport, Geum River Flood Control Office, No. 551, Gongju-si, \\ Chungcheongnam-do, Republic of Korea \\ ${ }^{3}$ Korea Environment Institute, 370 Sicheong-daero, Sejong-si, Republic of Korea
}

Correspondence should be addressed to Jang Hyun Sung; jhsung1@korea.kr

Received 19 July 2015; Revised 8 October 2015; Accepted 29 October 2015

Academic Editor: Milan Gocic

Copyright (C) 2016 Byung Sik Kim et al. This is an open access article distributed under the Creative Commons Attribution License, which permits unrestricted use, distribution, and reproduction in any medium, provided the original work is properly cited.

The Standardized Precipitation Evapotranspiration Index (SPEI) analysis was conducted using monthly precipitation data and temperature data on a $12.5 \mathrm{~km} \times 12.5 \mathrm{~km}$ resolution based on a Representative Concentration Pathways (RCP) 8.5 climate change scenario, and the characteristics of drought were identified by the threshold. In addition, the changes in drought severity and intensity were projected using the threshold based on the run-length concept and frequency analysis. As a result of the analysis, the probability density function of the total drought and maximum drought intensity moved the upper tail for the upcoming years, and the average drought intensity was also projected to become stronger in the future than in the present to the right side. Through this, it could be projected that the drought scale and frequency and the drought intensity will become severer over South Korea because of future climate change.

\section{Introduction}

Based on the recent research efforts on climate change, it is projected that South Korea will be one of the countries exposed to the risk of extreme natural disasters, such as heavy rainfall and drought, because of climate change. Since the announcement of the Fourth Assessment Report (AR4) of the Intergovernmental Panel on Climate Change (IPCC), climate change impact assessments have been carried out in South Korea using climate projection data [1-4]. To assess the extreme climate mostly represented by extreme precipitation, drought, and flood, various analyses were applied to a regional climate model or data using statistical downscaling [5-7]. The application results generally project that the probability distribution of extreme precipitation will move to the upper tail and that the drought severity and frequency will increase [8].

The drought starts from meteorological drought and leads to agricultural drought, hydrological drought, and socioeconomic drought; they are monitored or projected using various drought indexes depending on each purpose $[9,10]$. Among meteorological drought indexes, Standardized Precipitation Index (SPI) [11] is frequently used because of its simple requirements [12]. The evaluation and projection using SPI of meteorological drought indexes have been actively conducted for South Korea $[8,13]$. However, there are some limitations in the assessment of droughts that employs the meteorological drought index because of the multivariate characteristics of droughts. Thus, to consider multivariate drought, an integrated index dealing with various variables, such as runoff, soil moisture, and evapotranspiration, as well as precipitation, has been proposed and applied [14, 15]. Standardized Precipitation Evapotranspiration Index (SPEI) [16], which considers the demand (evapotranspiration) as well as the supply (precipitation), was suggested, and the meteorological drought is assessed in a more physical manner than SPI.

As it is difficult to define when the drought started and ended, previous researches assessed the risk of drought in an indirect way by conducting the frequency analysis of the 


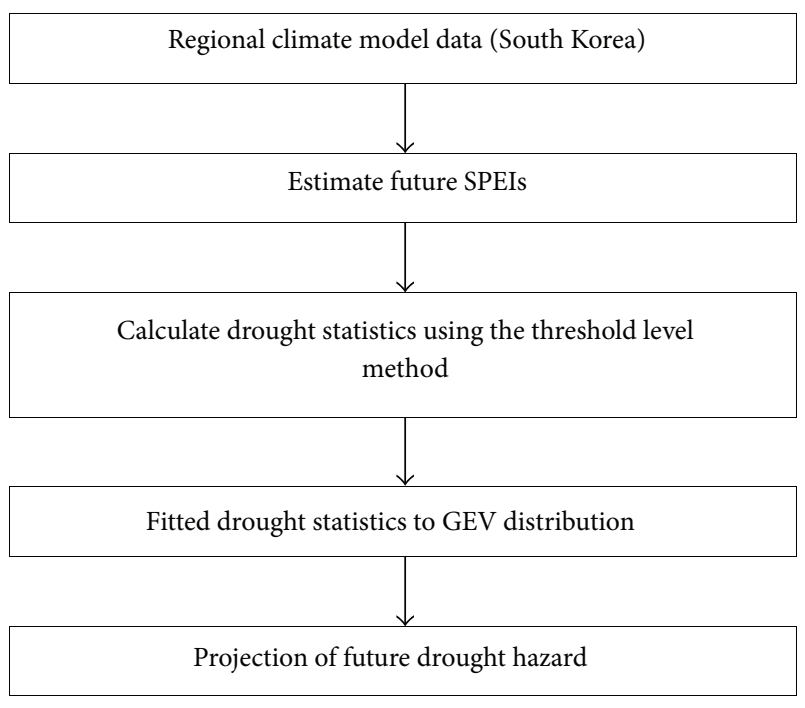

Figure 1: Procedure of this study.

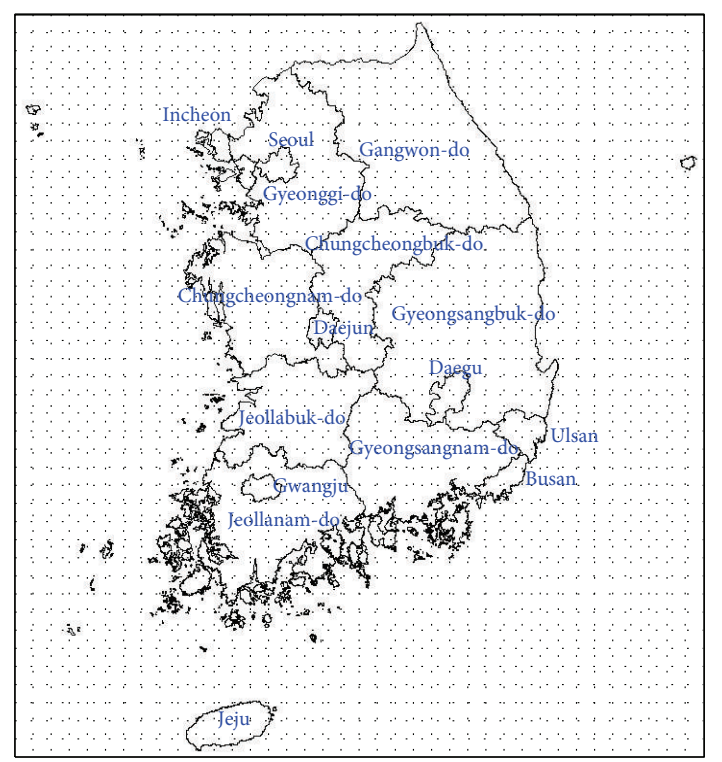

FIGURE 2: Location map including RCM grid and administrative division.

drought indexes $[10,17]$. Mishra and Singh [18] calculated the drought index for each nonexceedance probability by fitting the SPI value to an EV-1 (Extreme Value Type-1) distribution. Lee and Kim [17] derived drought severity-durationfrequency curves by fitting the annual minimum SPI to probability distribution as a random variable. Mishra and Singh [18] developed severity-area-frequency (SAF) curves for annual droughts by climate change. Most researches in the field considered only the annual minimum value and temporary severity of the drought. However, as the drought is multiscale, the analysis of important variables, such as the magnitude, intensity, and duration of the drought, must be conducted. This study aimed to project future SPEI using RCP8.5 projection data. Since 2014, South Korea has been

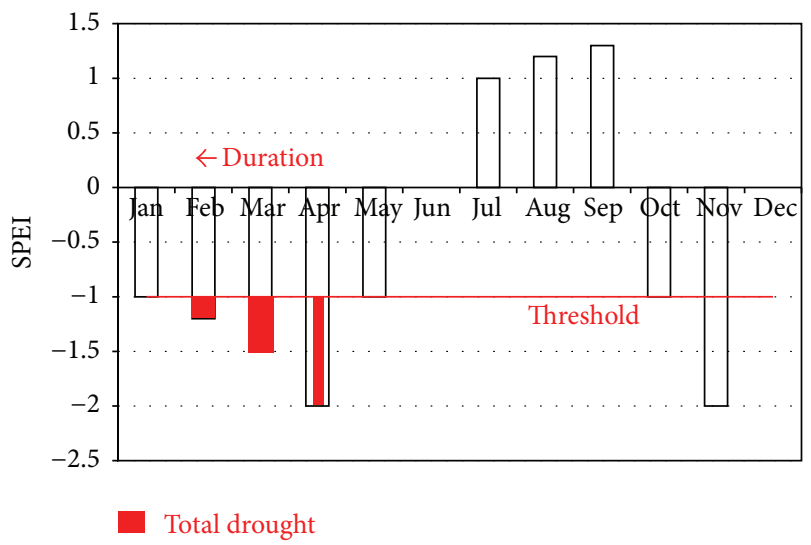

FIGURE 3: Definition of total drought, maximum drought intensity, and drought magnitude.

suffering from extreme drought; thus, this study projected change in extreme droughts under extreme scenarios. In addition, the drought characteristics by the threshold level to the projected SPEI were identified. This study also projected the drought risk of each administrative division of South Korea in the 21st century by fitting the drought characteristics to the Generalized Extreme Value (GEV) distribution.

\section{Theoretical Background and Study Area}

2.1. SPEI and Threshold Level. Because SPI does not consider the variables related to temperature, it has a limitation of being unable to consider the change in demand, such as the change in water budget, like the precipitation and evapotranspiration by climate variation. However, SPEI is similar to SPI but can reflect the effect of not only the variability in precipitation but also the variability of evapotranspiration. Thus, this study used SPEI. SPEI is the difference between the random month $i$ and PET obtained by using the precipitation and the Thornthwaite equation $[19,20]$, as shown in

$$
D_{i}=P_{i}-\mathrm{PET}_{i}
$$

which is synthesized in each time scale like

$$
D_{n}^{k}=\sum_{i=0}^{k-1} P_{n-i}-\operatorname{PET}_{n-i} .
$$

Here, $k$ is the time scale of synthesis, and $n$ is the month used for calculation. The total drought, maximum drought intensity, and drought magnitude were calculated using SPEI (Figure 3). Negative SPEIs mean the dry condition; a drought event is defined when the SPEI is continuously negative and reaches a value of " -1.0 " or less [16]. Thus, it is assumed that " -1.0 " is the threshold level and that the drought starts in the level lower than " -1.0 " in monthly SPEI. The aggregate of SPEI while one drought event lasts was defined as total drought, and the maximum SPEI during the drought was defined as maximum drought intensity. The drought magnitude was obtained by dividing the total drought by drought duration. The aggregate of SPEI while one drought 


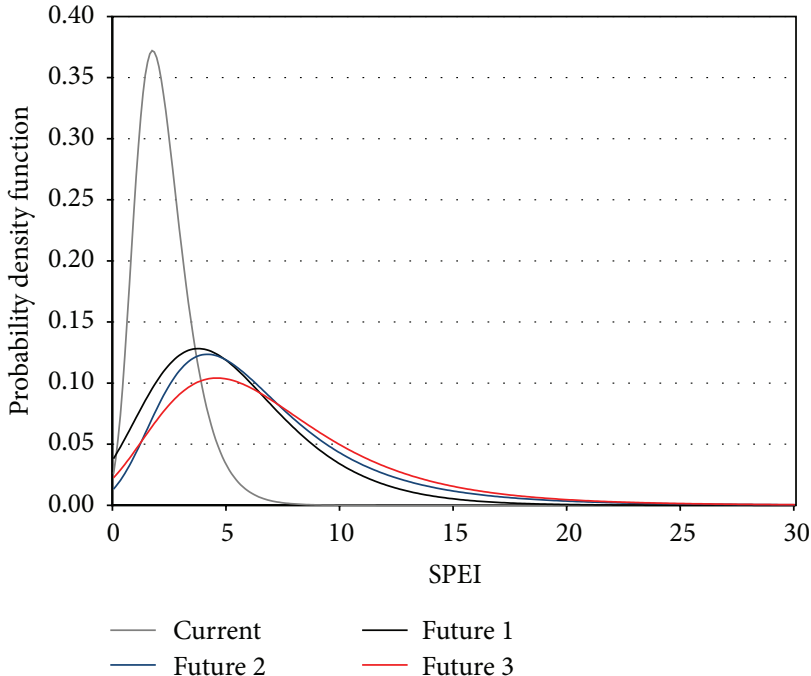

(a) Gangwon-do

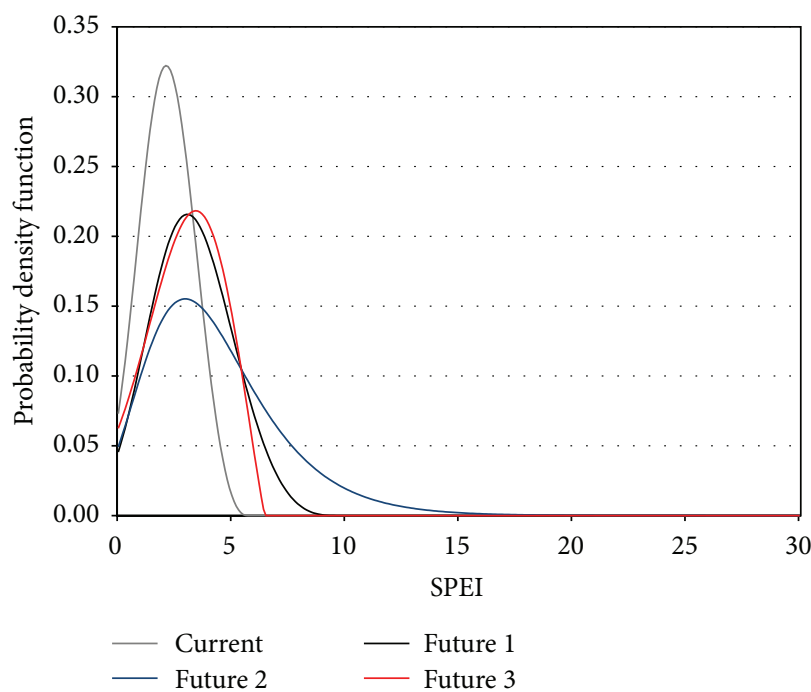

(c) Gyeongsangnam-do

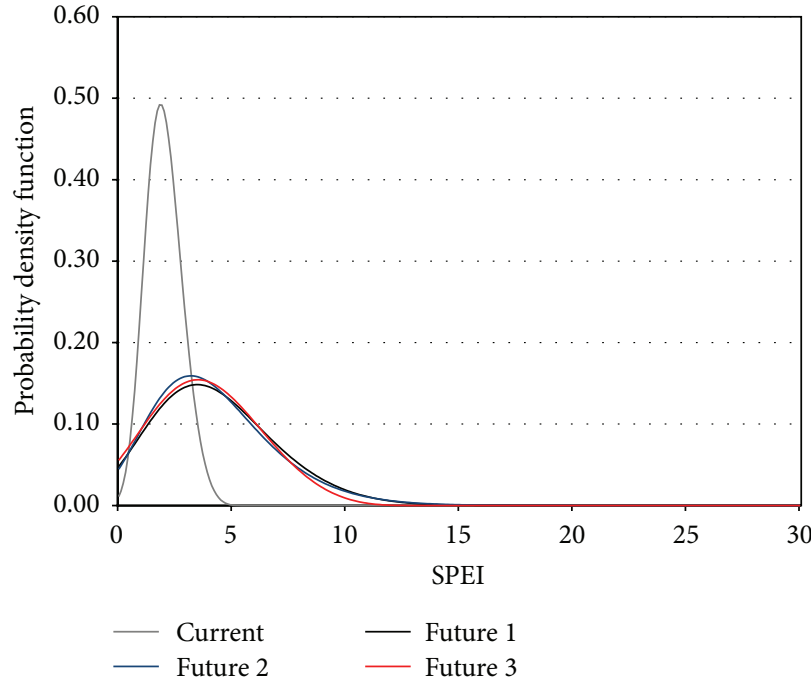

(e) Jeollanam-do

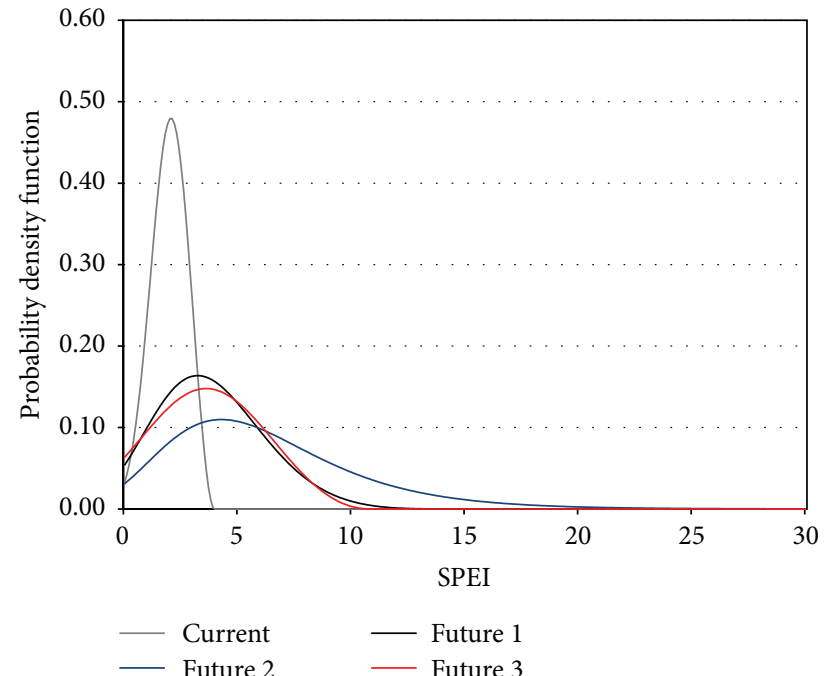

(b) Gyeonggi-do

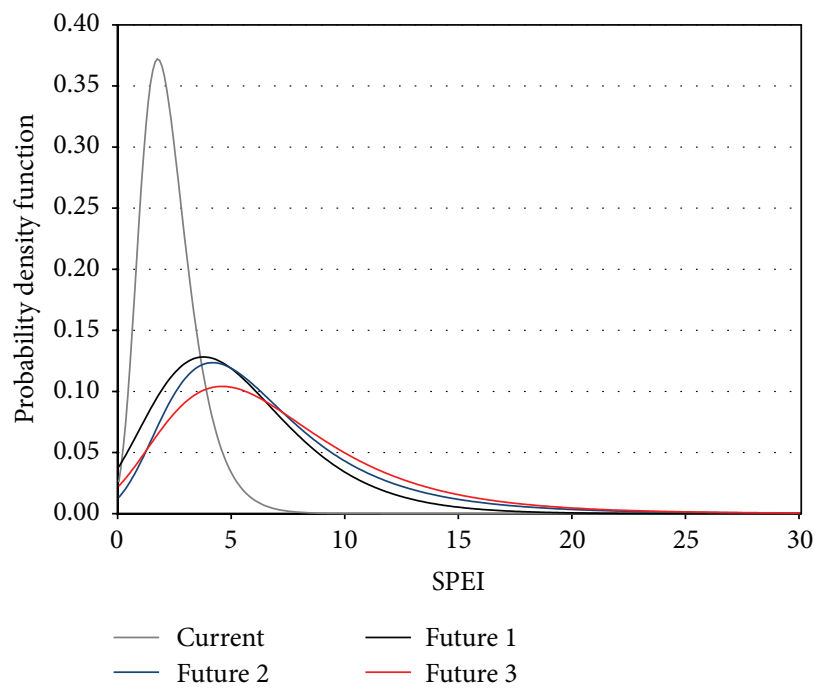

(d) Gyeongsangbuk-do

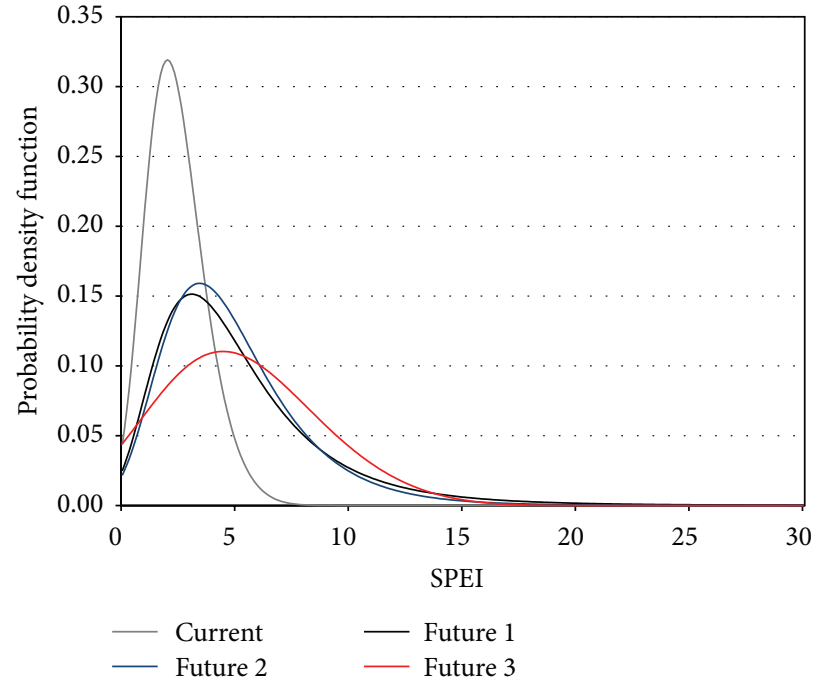

(f) Jeollabuk-do

Figure 4: Continued. 


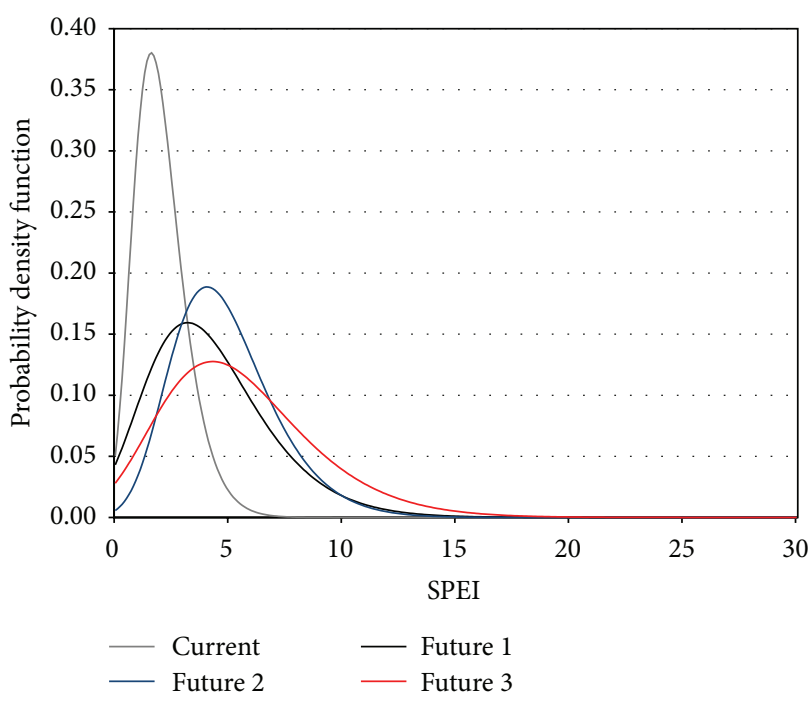

(g) Chungcheongnam-do

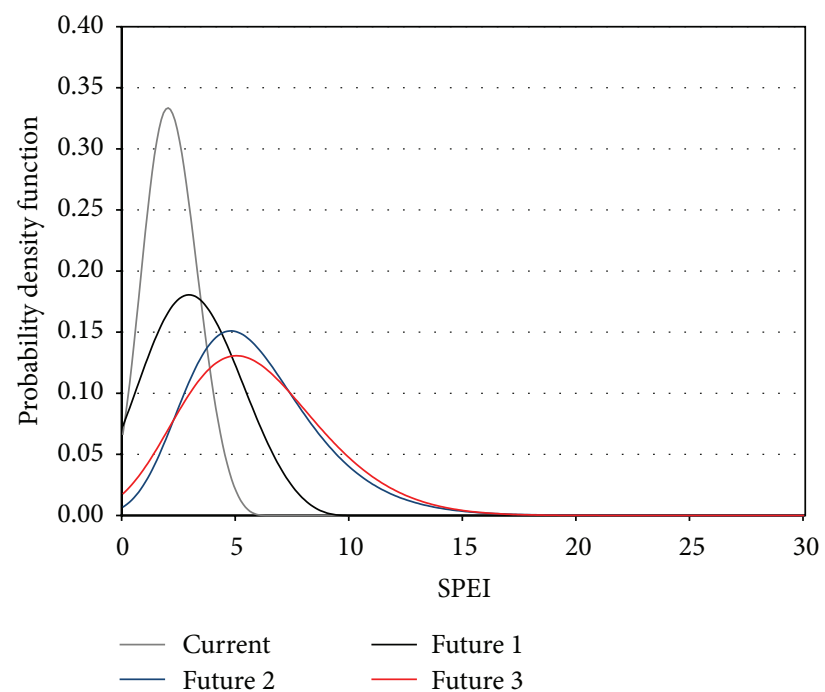

(h) Chungcheongbuk-do

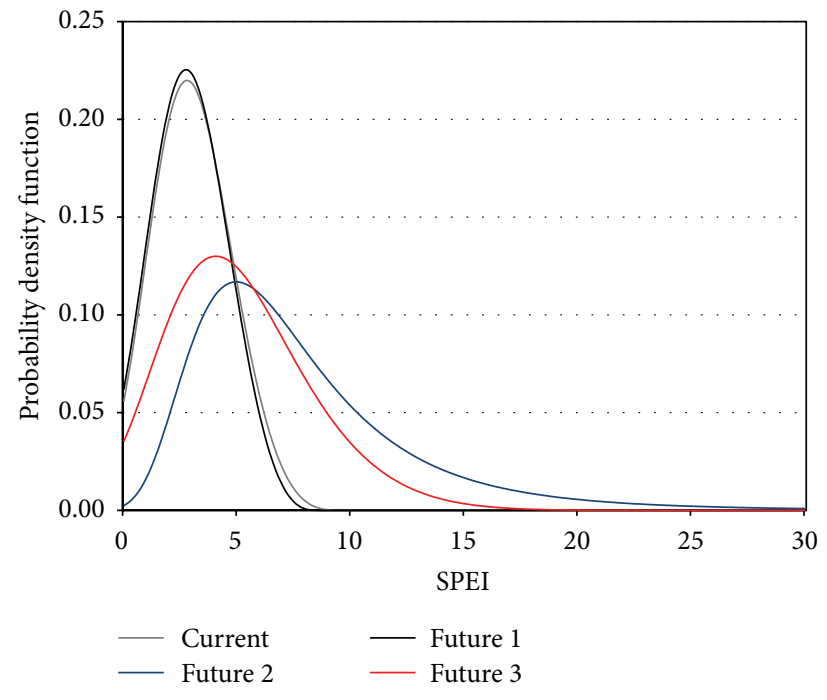

(i) Jeju

FIGURE 4: GEV PDF projection of total drought according to administrative division.

event lasts was defined as total drought, and the maximum SPEI during the drought was defined as maximum drought intensity. The drought magnitude was obtained by dividing the total drought by drought duration.

2.2. Methodology. Figure 1 shows the research procedure in this study. First, this study projected the SPEI of South Korea in the future by collecting the grid data of the HadGEM3RA-the representative regional climate model provided by the Korea Meteorological Administration (KMA). The climate of South Korea is composed of four seasons: spring, summer, autumn, and winter. South Korea's winter is influenced by the Siberian air mass, while its summer is hot and humid because of the maritime Pacific high and monsoon. With this, South Korea has been suffering extreme drought recently. By applying the threshold level to future
SPEI monthly time series, the drought characteristics were calculated, and the changes of the risk for future drought characteristics were projected using frequency analysis. The HadGEM3-RA [21] used in this study is a regional climate model produced from the global atmosphere-ocean combination model scenario (HadGEM2-AO, resolution: $135 \mathrm{~km}^{2}$ ) based on Representative Concentration Pathways (RCP) (Figure 2).

\section{Results and Discussion}

3.1. Results. Figures 4-6 show the projection of the Probability Density Function (PDF) of the GEV distribution in current climate and future climate for total drought, maximum drought intensity, and drought magnitude. This study takes the absolute value of total drought, maximum 

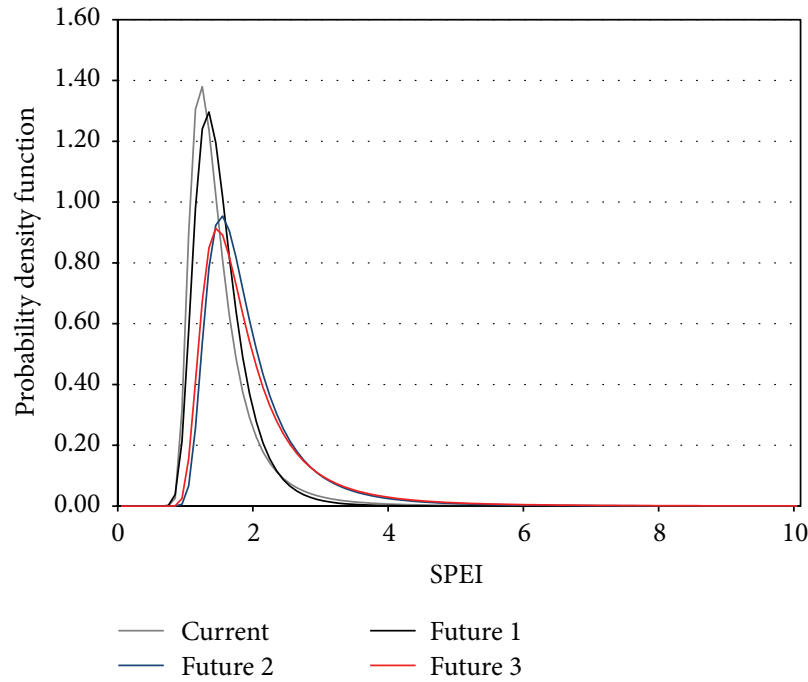

(a) Gangwon-do

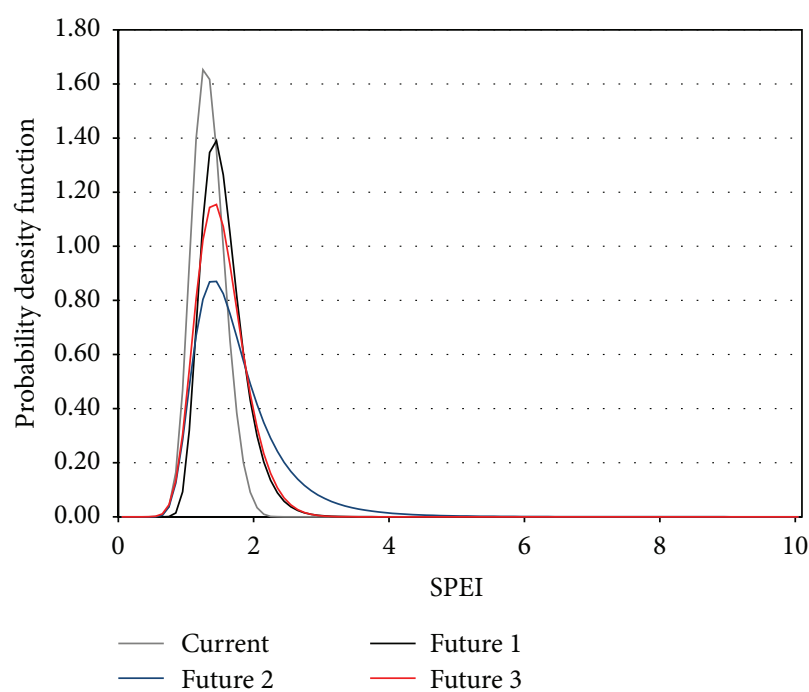

(c) Gyeongsangnam-do

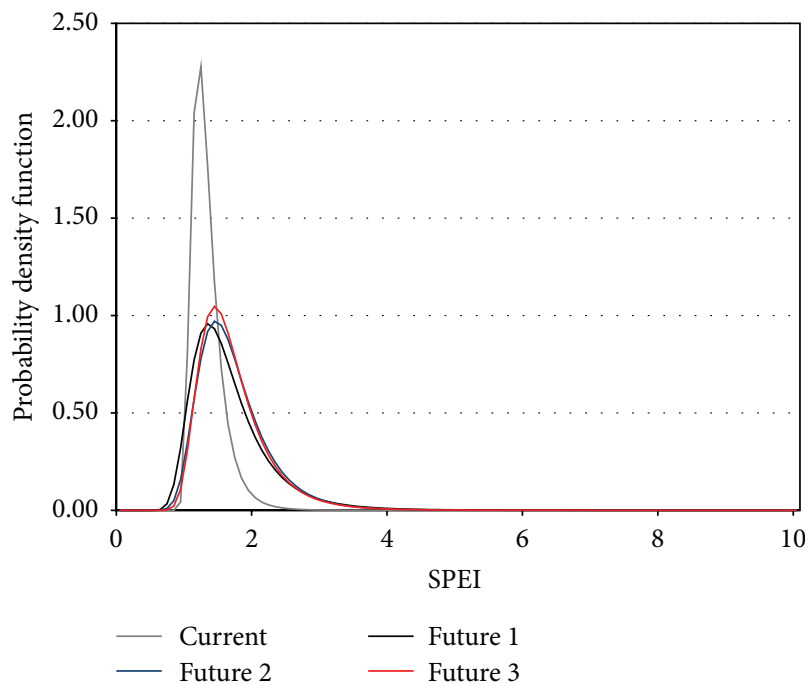

(e) Jeollanam-do

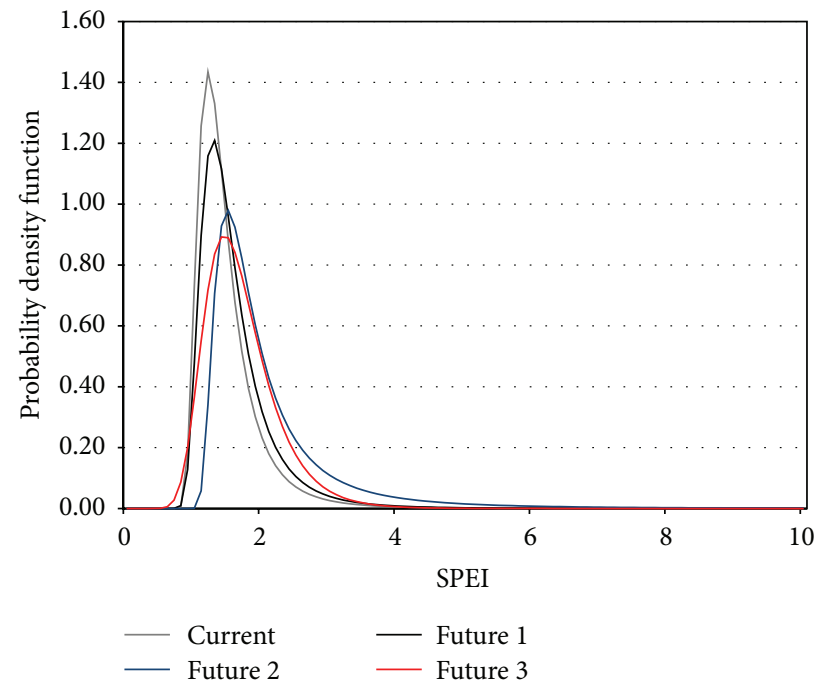

(b) Gyeonggi-do

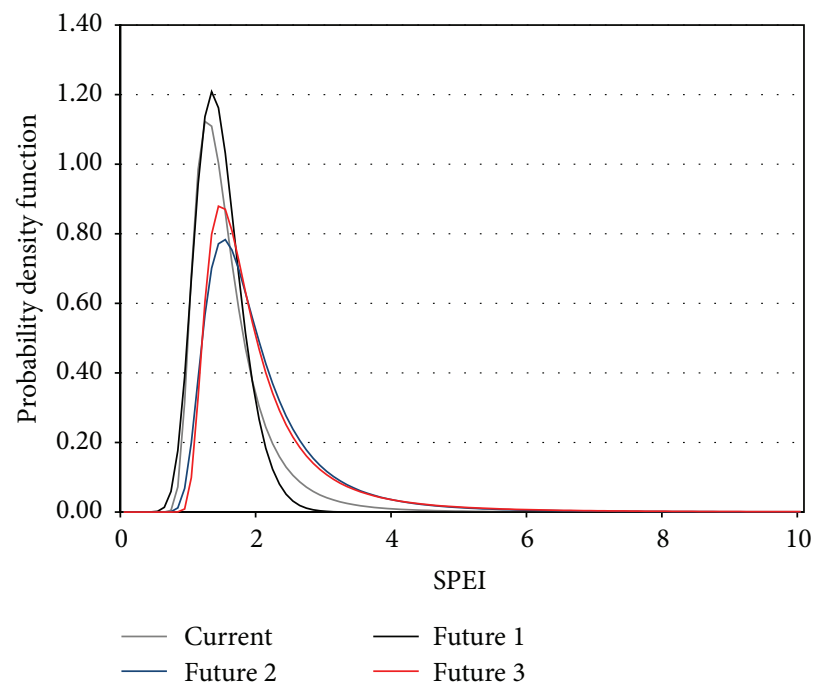

(d) Gyeongsangbuk-do

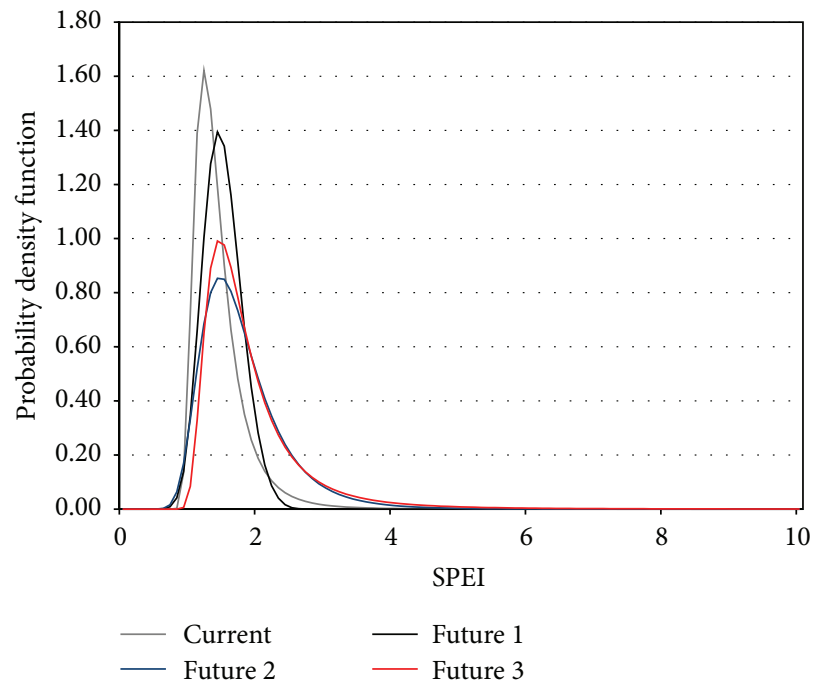

(f) Jeollabuk-do

FIgURE 5: Continued. 


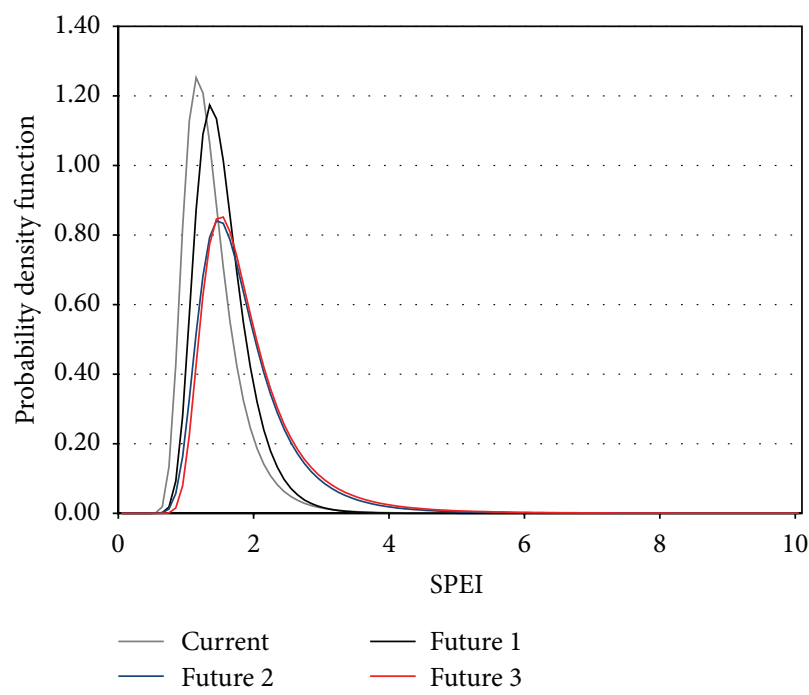

(g) Chungcheongnam-do

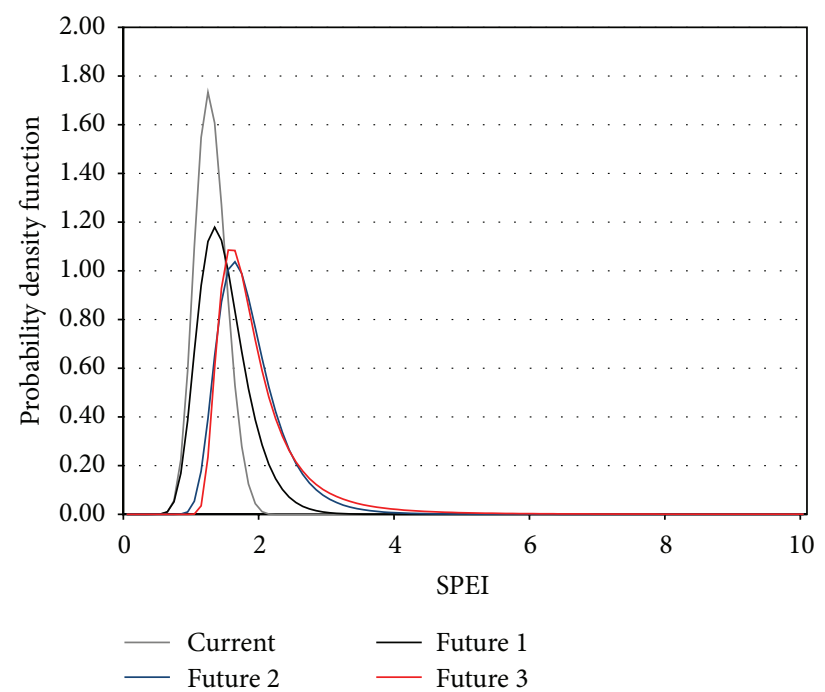

(h) Chungcheongbuk-do

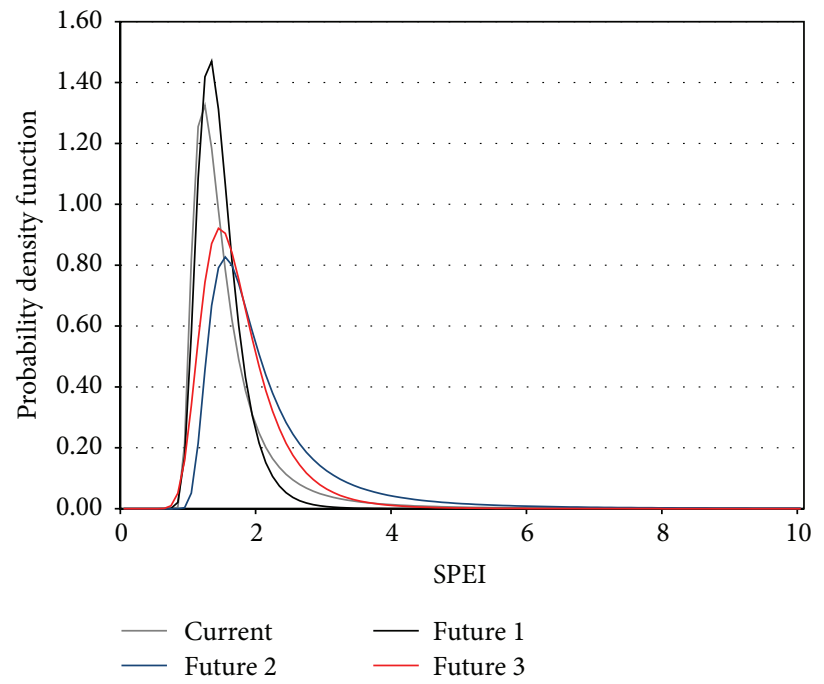

(i) Jeju

FIGURE 5: GEV PDF projection of maximum drought intensity according to administrative division.

drought intensity, and drought magnitude; these absolute values follow GEV Type II (Frechet) having right tail. Thus, we fitted drought statistics to GEV distribution regardless of goodness-of-fit test.

In this study, the period from 1980 to 2005 is referred to as current climate, from 2011 to 2040 as Future 1, from 2041 to 2070 as Future 2, and from 2071 to 2100 as Future 3. It was projected that the PDF of total drought GEV distribution will generally show a continuously increasing location and scale parameters in the future. If the shape parameter becomes smaller, the upper tail of the GEV distribution at the upper tail becomes thicker. This means the extreme event occurs more frequently. In addition, the shape parameter of some regions was smaller in the middle part of the 21st century than the later part of the said century. Therefore, the frequency of total drought occurrence on a larger scale was higher in the middle part of the 21st century. This phenomenon of reversal was identified in Gyeonggi-do, Gyeongsangnam-do, Jeollanamdo, and Jeju-do, and this phenomenon is considered to have been caused by more average precipitation in the middle part of the 21st century.

The maximum drought intensity relates to temporary maximum intensity or maximum severity during the drought period; for example, the SPEI of the month when the drought was the severest in a year, and it is the random variable that was used most frequently so far in the risk assessment using drought index. Figure 5 shows the PDF of the maximum drought intensity in the current and future climates, and according to this figure, the location and scale parameters grew increasingly larger in the future. In all regions, the drought of comparatively stronger intensity than the maximum drought intensity in the current climate 


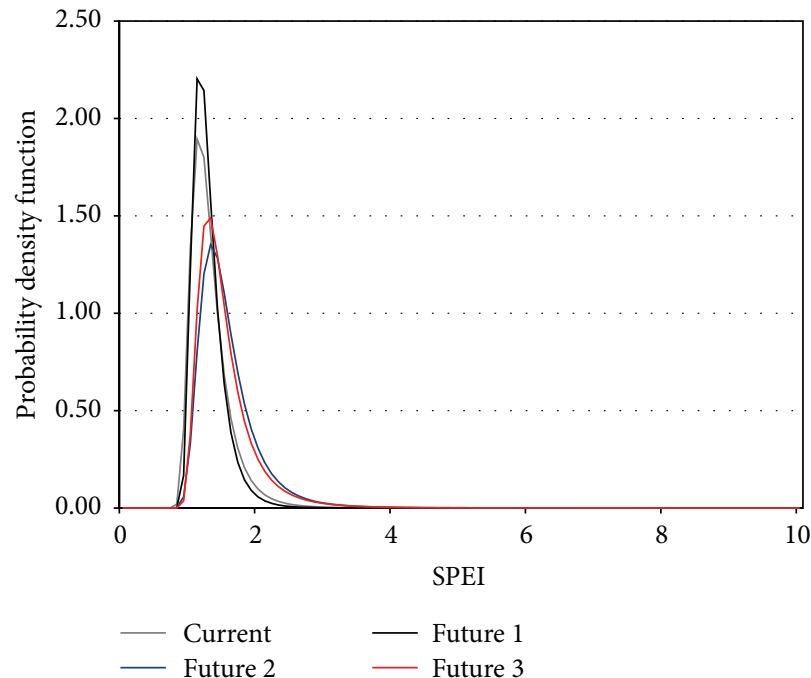

(a) Gangwon-do

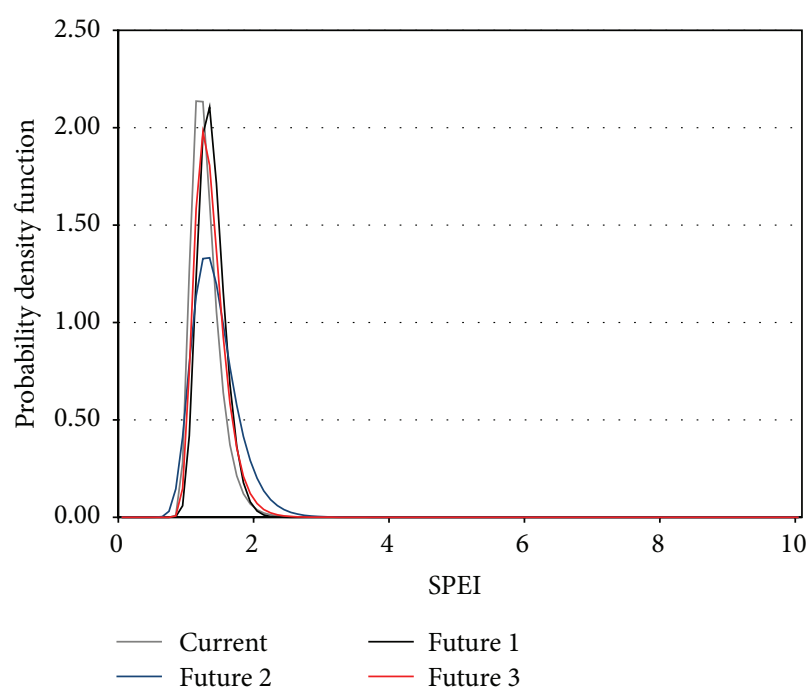

(c) Gyeongsangnam-do

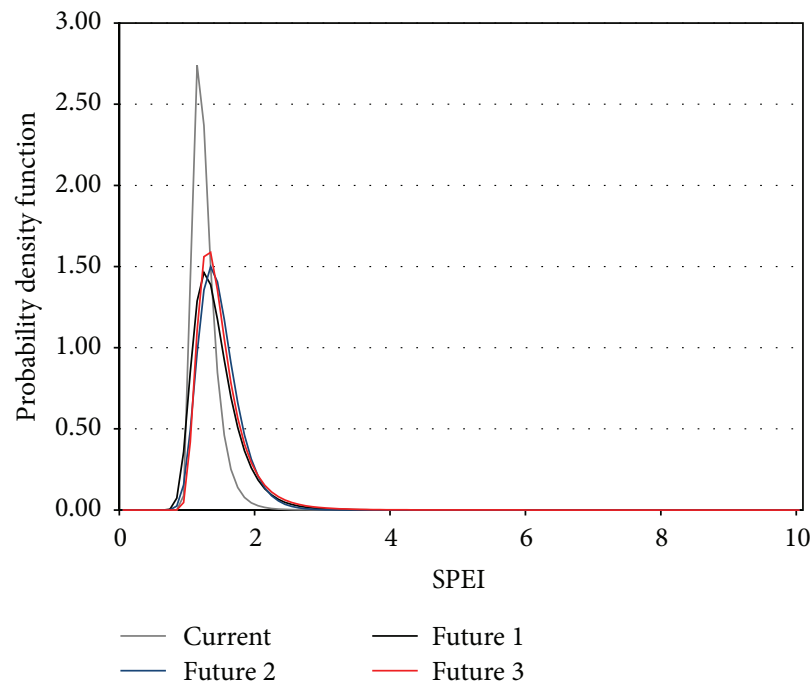

(e) Jeollanam-do

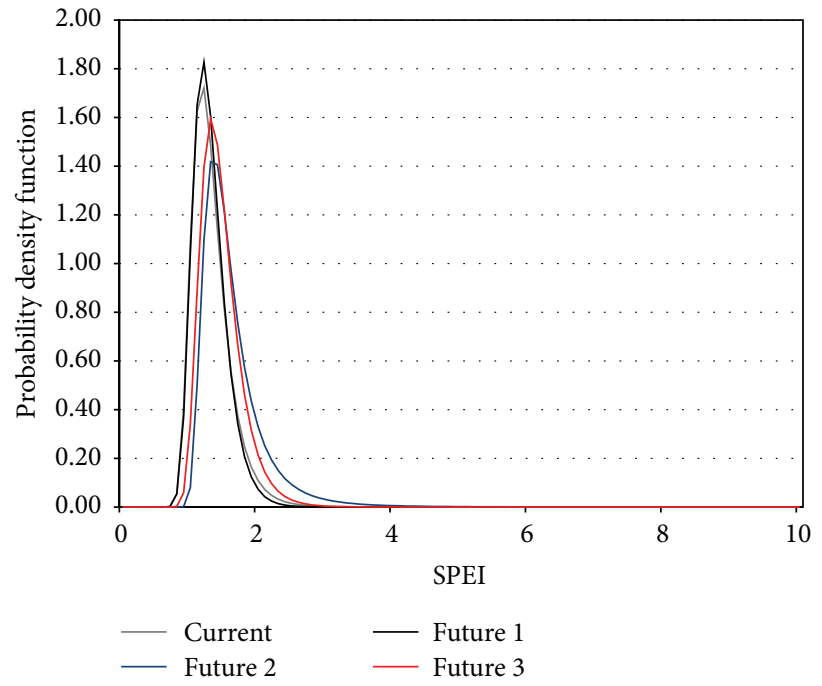

(b) Gyeonggi-do

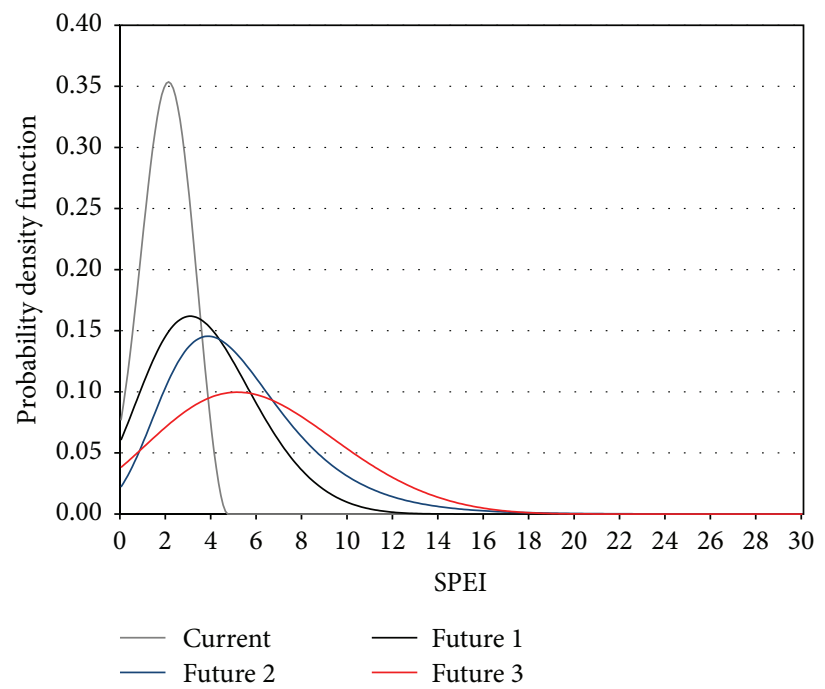

(d) Gyeongsangbuk-do

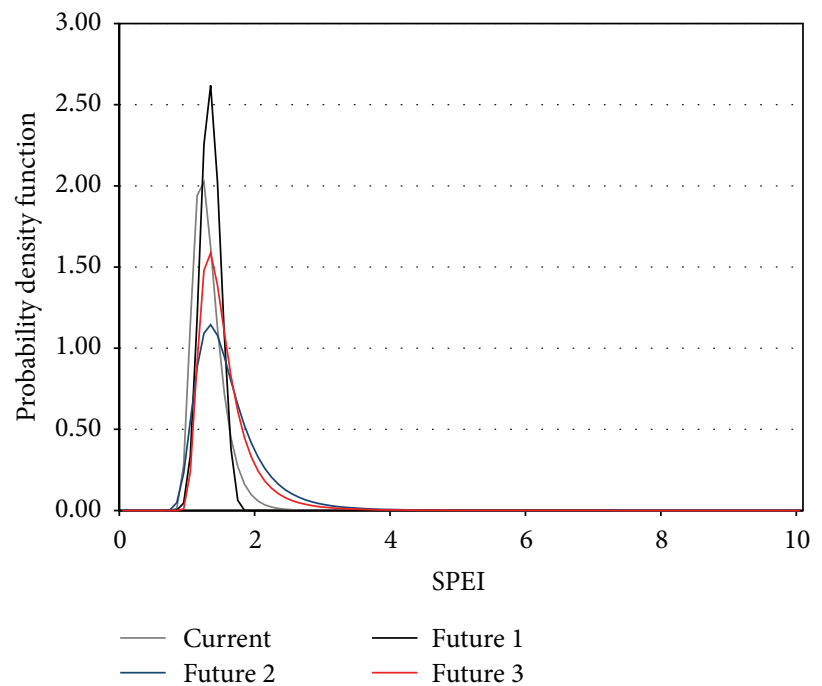

(f) Jeollabuk-do

Figure 6: Continued. 


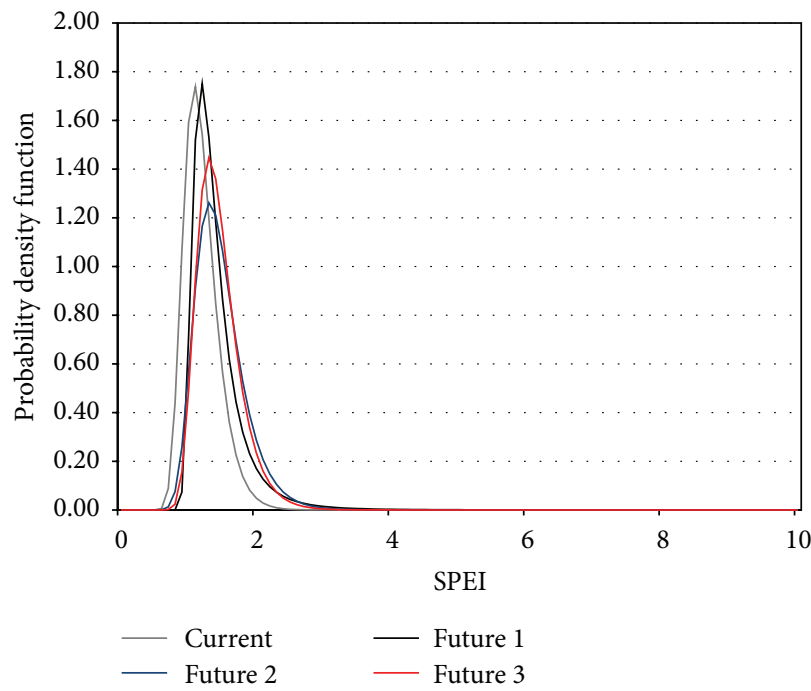

(g) Chungcheongnam-do

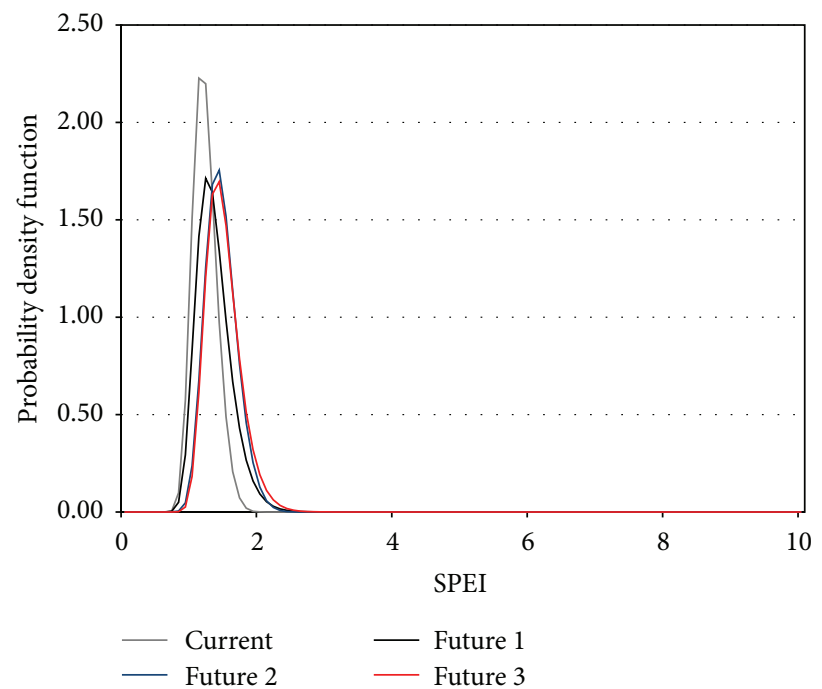

(h) Chungcheongbuk-do

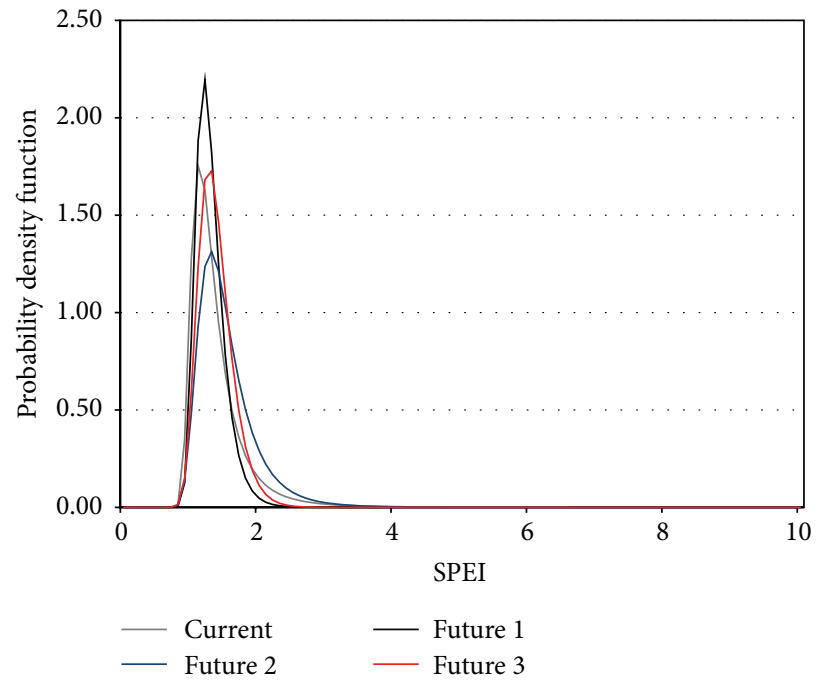

(i) Jeju

FIGURE 6: GEV PDF projection of drought magnitude according to administrative division.

was projected. This result corresponds with previous studies [22-24]. According to the analysis result, the average and variation of the maximum drought intensity are increasing, which indicates that the average of the drought having strong intensity will further increase in the future and that the droughts of much stronger intensity will occur among the droughts of strong intensity, and droughts of much weaker intensity will occur among the droughts of weaker intensity. The special trend of the shape parameter related to the occurrence frequency was not identified, but the drought intensity in Gyeonggi-do, Gyeongsangnam-do, and Jeju-do was stronger in the middle part of the 21st century than the later part of the said century. The total drought in Jeollanamdo Province showed more reversal phenomena in the middle part of the 21st century than in the later part of the said century; however, the maximum drought intensity showed no significant difference between the middle and later parts of the 21st century, which means that many total droughts will occur in Jeollanam-do Province in the middle part of the 21st century, but they will have no considerably strong intensity.

Similar to this, as the maximum drought intensity, the location and scale parameters of the drought magnitude (obtained by dividing the total drought by duration) were becoming increasingly larger in the future, and the shape parameter was projected to increase to more than its level in the current climate in all locations except Jeju-do. The drought magnitude (the same concept as precipitation intensity) relates to the intensity for unit time. It is generally projected that the intensity of the precipitation will become increasingly stronger in the future; the drought intensity was also projected to become stronger in the future. The magnitude of the total drought in Gangwondo, Gyeongsangbuk-do, Jeollabuk-do, Chungcheongnamdo, and Chungcheongbuk-do was projected to become 

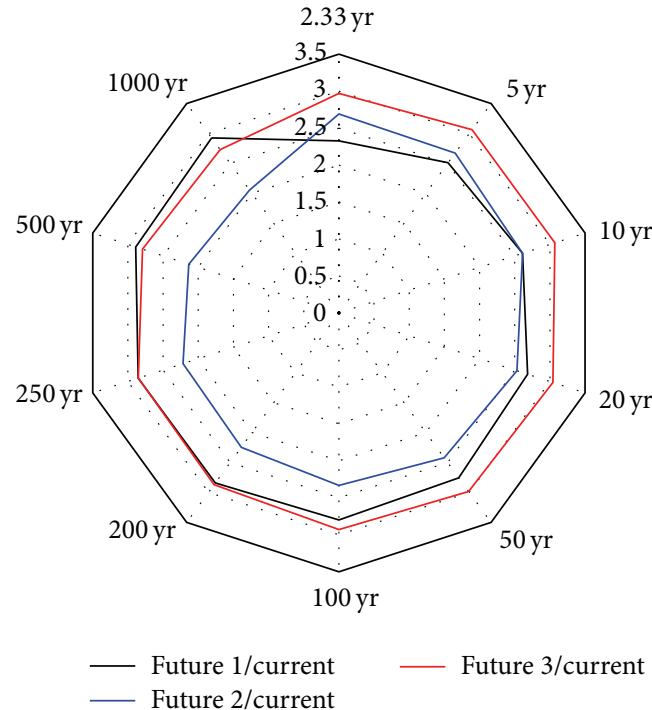

(a) Gangwon-do
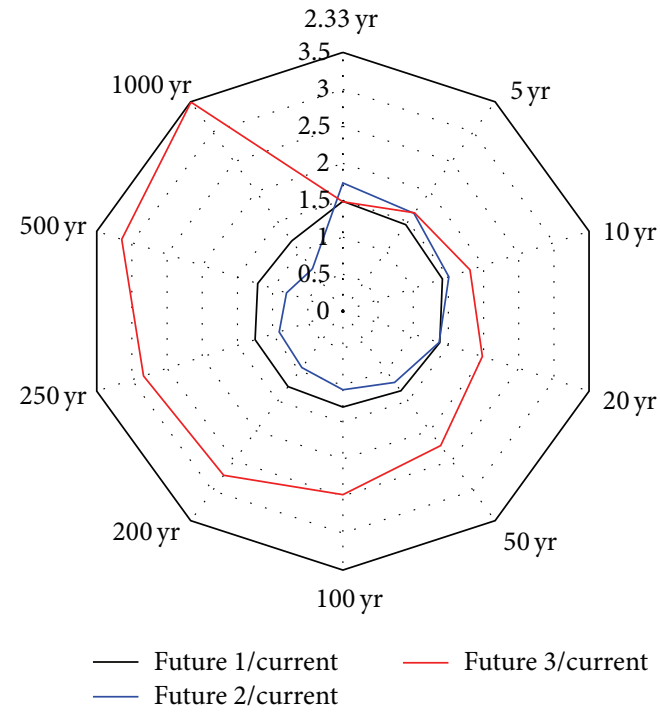

(c) Gyeongsangnam-do

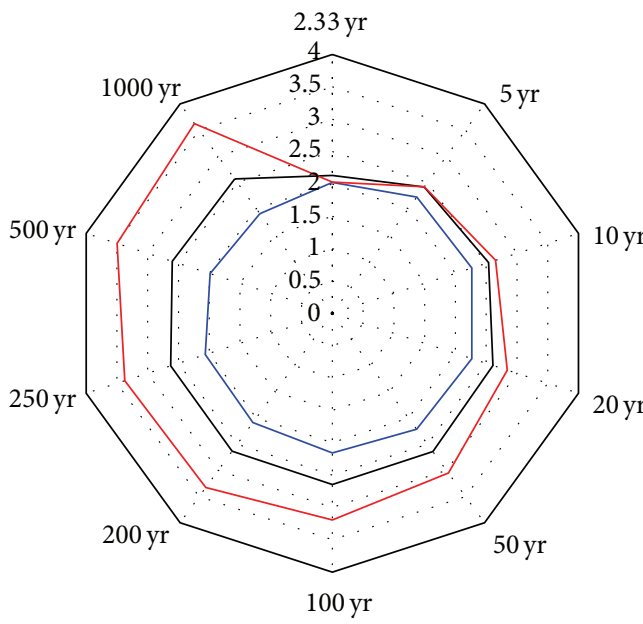

Future 1/current
Future 2/current

(e) Jeollanam-do
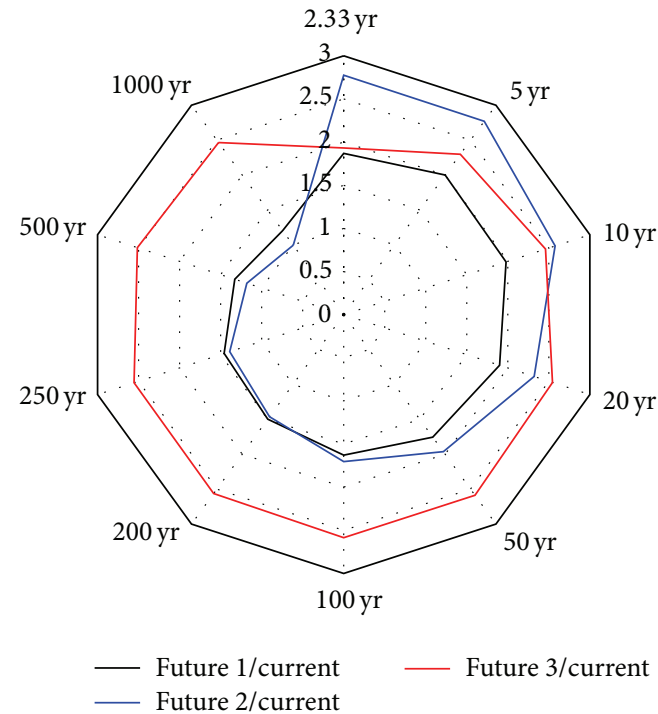

(b) Gyeonggi-do
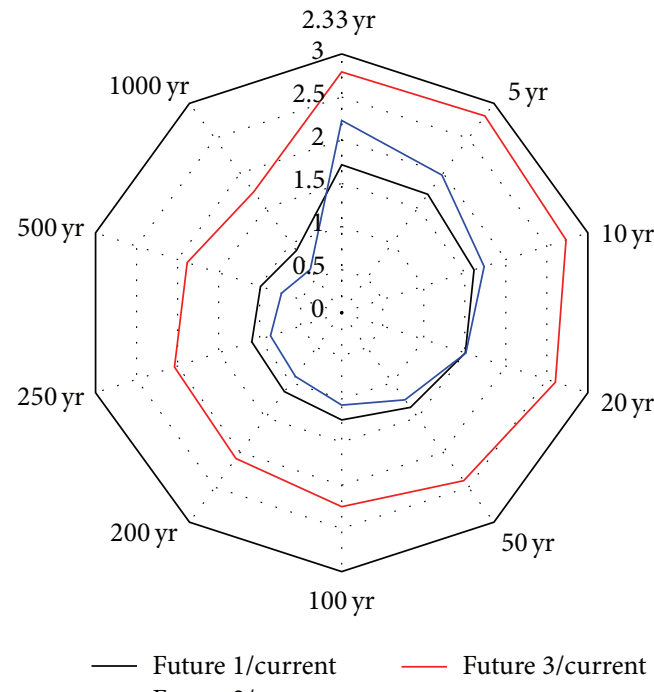
- Future 2/current

(d) Gyeongsangbuk-do

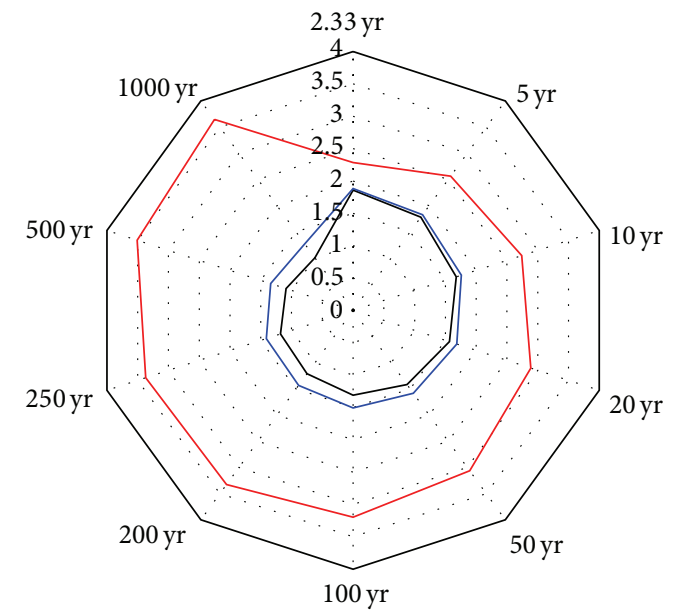

- Future 1/current $\quad$ Future 2/current

(f) Jeollabuk-do

Figure 7: Continued. 


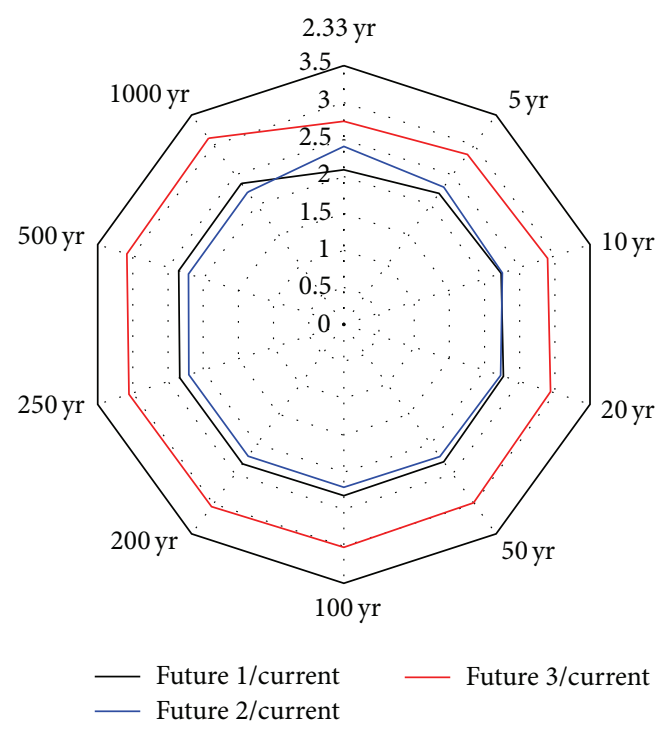

(g) Chungcheongnam-do

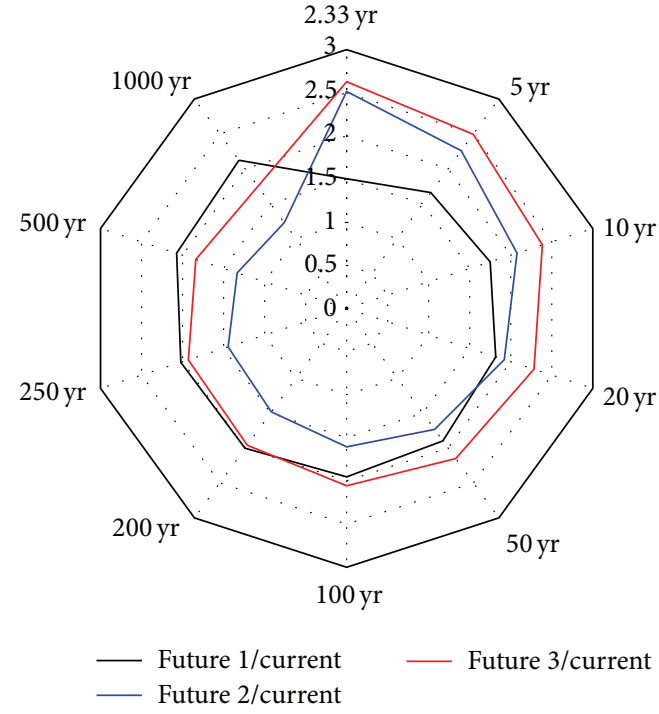

(h) Chungcheongbuk-do

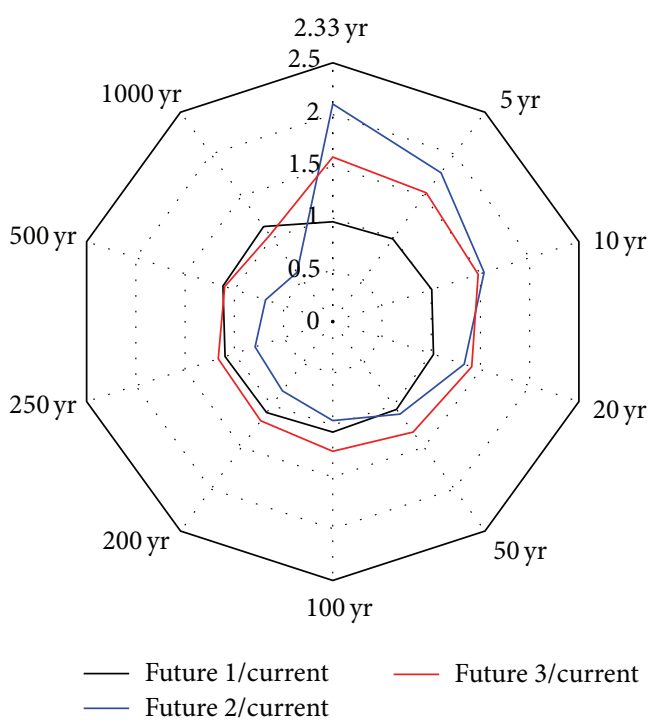

(i) Jeju

Figure 7: Ratio of total drought in the future climate to the current climate.

increasingly larger in the future, but the drought magnitude in Gangwon-do, Gyeongsangbuk-do, Jeollabuk-do, and Chungcheongnam-do was comparatively smaller in the later part than the middle part of the 21st century, which indicates that the number of dry days in the relevant regions will increase or the under-anomaly of the precipitation will continue for a longer period (Figure 6).

Figure 7 shows the rate of increase of total drought in each administrative division in the future climate compared to the current climate according to recurrence period. The possibility of total drought of the later part of the 21st century was projected to be high in Gyeonggi-do, Gyeongsangnamdo, Jeollanam-do, Jeollabuk-do, and Chungcheongnam-do and that of the first part of the 21st century in Gangwon-do and Chungcheongbuk-do was projected to be high as well but only in some recurrence periods. In general, however, the total drought showed the trend of a higher increase in the future climate than in the current climate. The rate of increase became increasingly larger in the future, and it was projected (based on a 100-year frequency) that the rate will increase about three times from the current climate in Gyeongsangnam-do, Jeollanam-do, and Jeollabuk-do.

Figure 8 shows the rate of increase of drought intensity in the future climate compared with the current climate in each administrative division according to recurrence period. Because of its great randomness through the use of the annual lowest SPEI, the rate of increase in future climate compared with the current climate did not show a significant trend other than the total drought; however, in Gyeonggido, Gyeongsangnam-do, and Jeju-do, the maximum drought intensity was projected to be stronger in the later part of the 21st century, and in Gangwon-do and Chungcheongnam-do, 

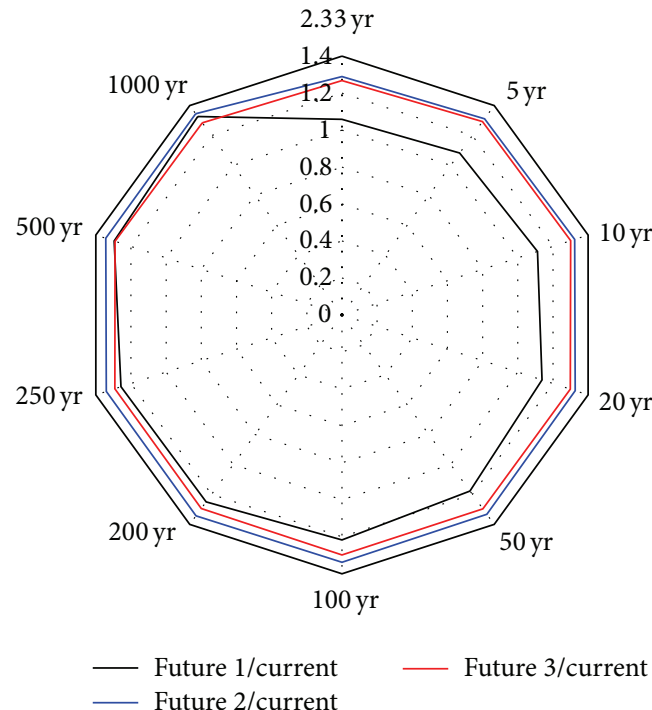

(a) Gangwon-do
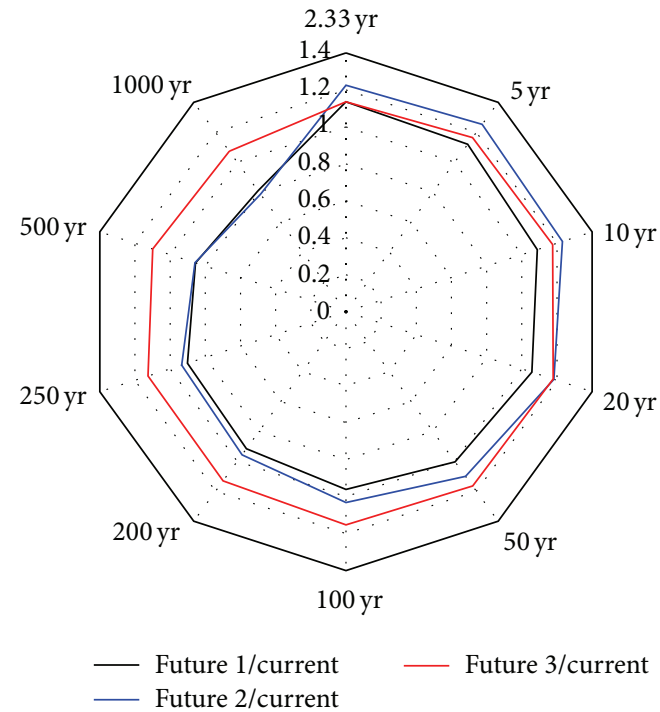

(c) Gyeongsangnam-do

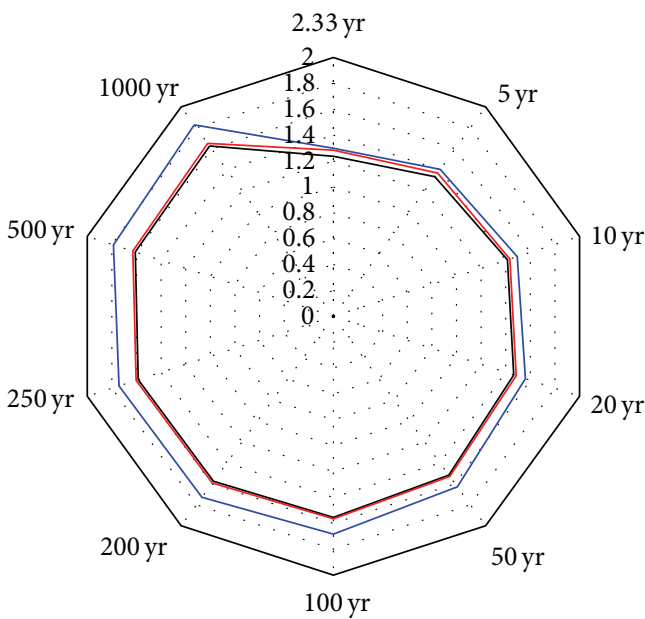

Future $1 /$ current
Future $2 /$ current

(e) Jeollanam-do
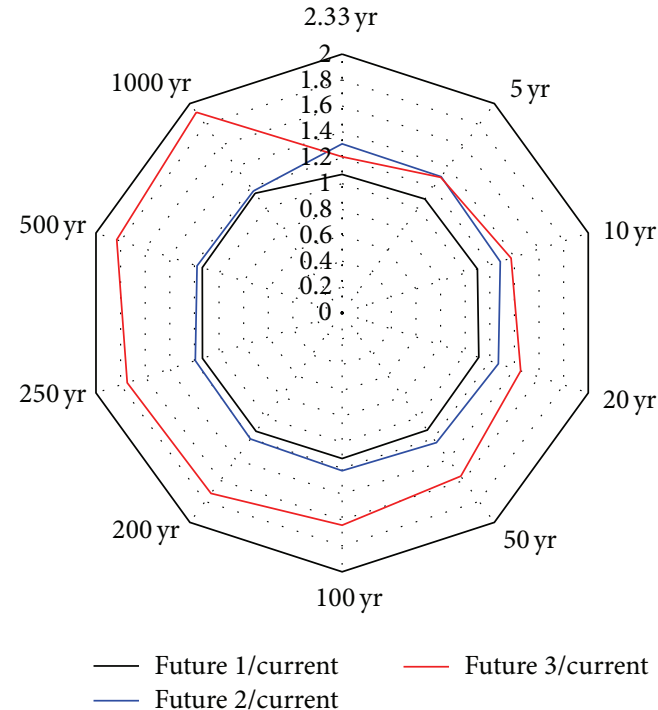

(b) Gyeonggi-do
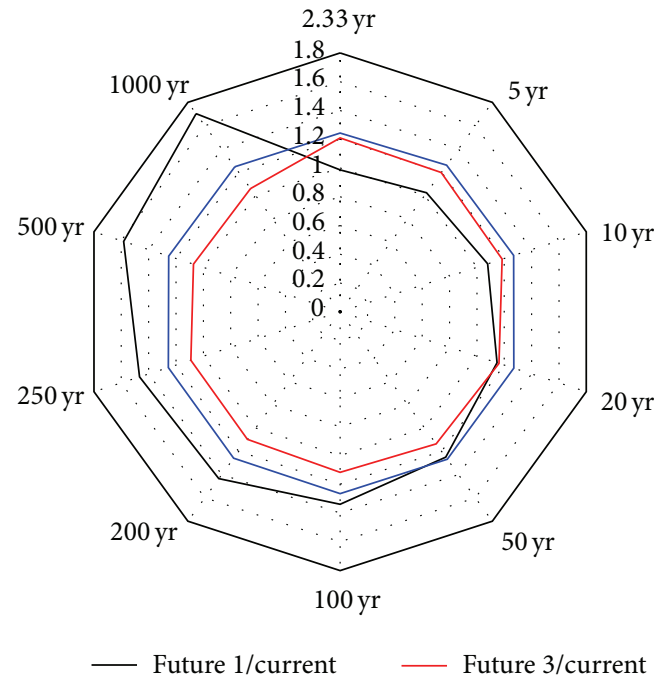
- Future 2/current

(d) Gyeongsangbuk-do

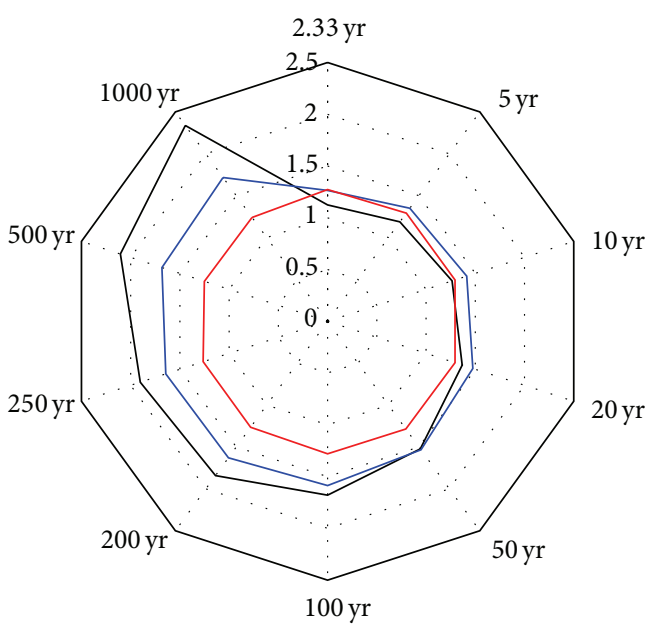

Future 1/current — Future 3/current Future 2/current

(f) Jeollabuk-do

Figure 8: Continued. 


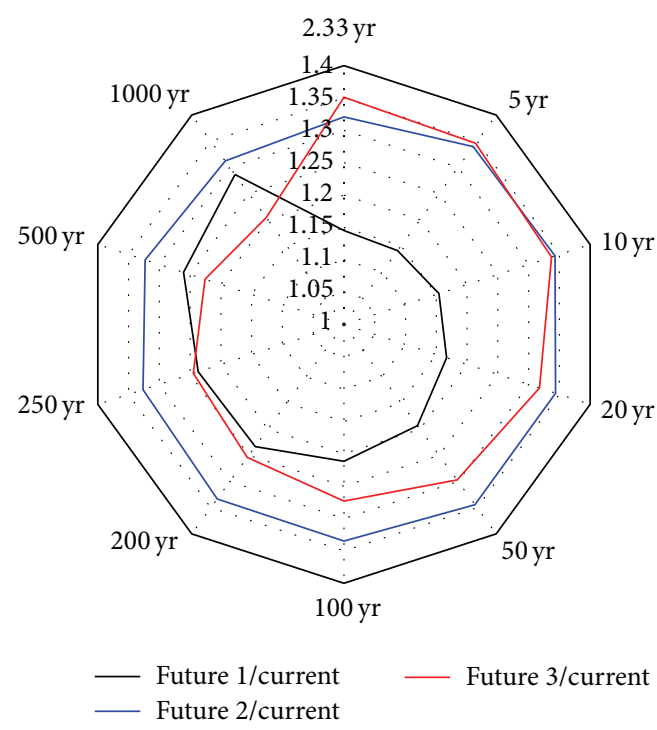

(g) Chungcheongnam-do

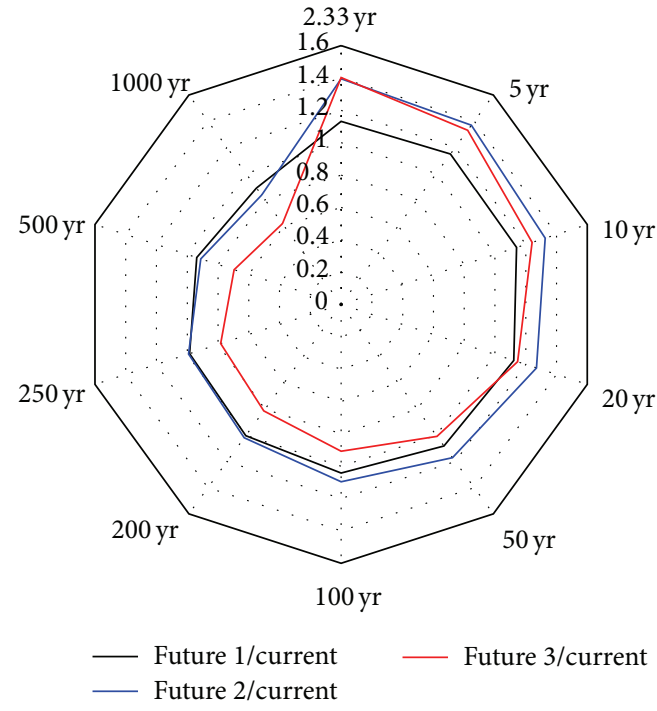

(h) Chungcheongbuk-do

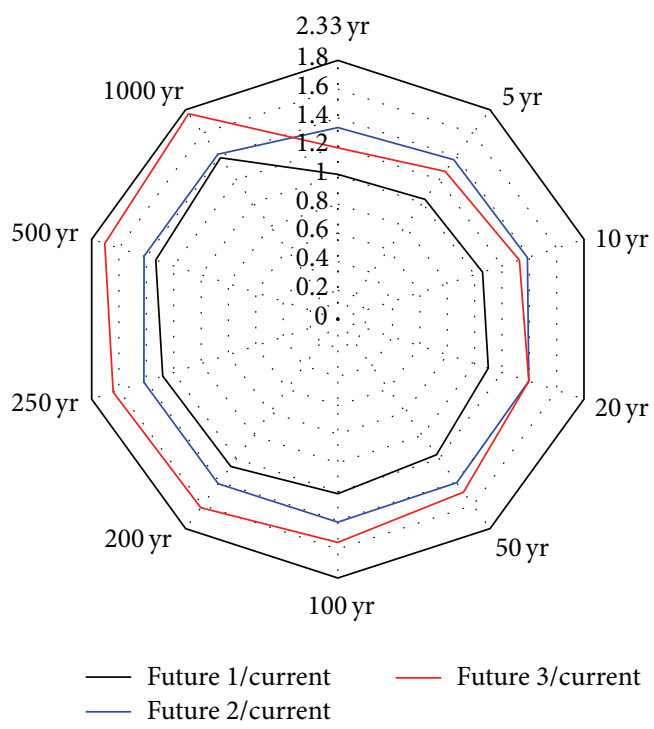

(i) Jeju

FIGURE 8: Ratio of maximum drought intensity in the future climate to the current climate.

the maximum drought intensity was projected to be stronger in the middle part of the 21st century. In general, it was projected that the maximum drought intensity will become stronger in the future than the present, but the opposite trend was identified in Chungcheongbuk-do Province.

Figure 9 shows the drought magnitude in the future compared with the current in each administrative division according to recurrence period. In Gangwon-do, Gyeongsangnam-do, Jeollanam-do, Chungcheongnam-do, and Chungcheongbuk-do, the drought magnitude was projected to be larger in the middle part than the later part of the 21st century, and in Gangwon-do and Jeju-do, the drought magnitude was projected to be larger in the later part than the middle part of the 21st century. Based on a 100-year frequency, the drought magnitude was projected to increase about 1.8 times from the present in Jeollanam-do Province in the middle part of the 21st century. The climate model is known to have better estimation capability for the temperature than the precipitation. In view of that, the variable that shows an increasingly dramatic trend of increase in the future is the temperature. SPEI is the drought index that considers the difference between precipitation and evapotranspiration, with evapotranspiration as the function of temperature. The stronger drought magnitude in the middle part than the later part of the 21st century indicates that there is a considerably small level of precipitation in the middle part of the 21st century regardless of the increase of evapotranspiration.

3.2. The Result of the Change in the Threshold Level. The drought size in the current and future climates was calculated while changing the drought standard, that is, the threshold level, to " -1 " and " -1.5 " (Figure 10). The total drought in " -1 " 

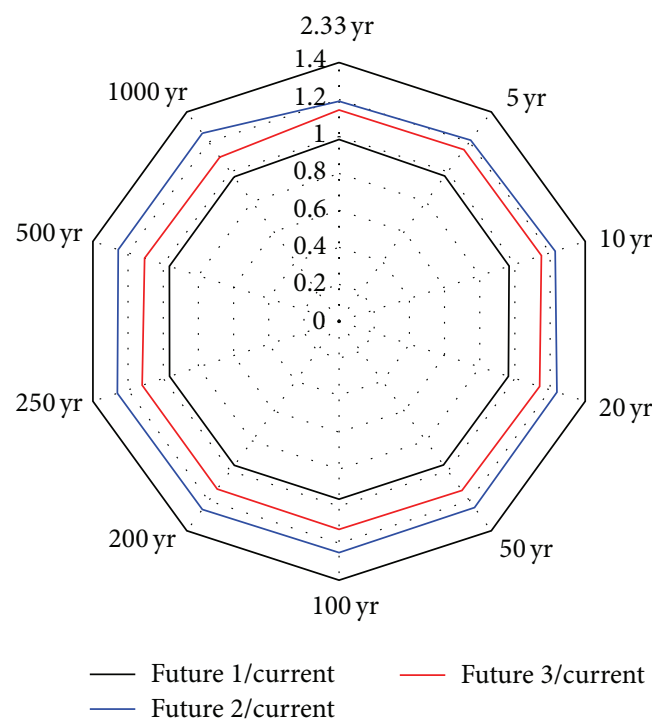

(a) Gangwon-do
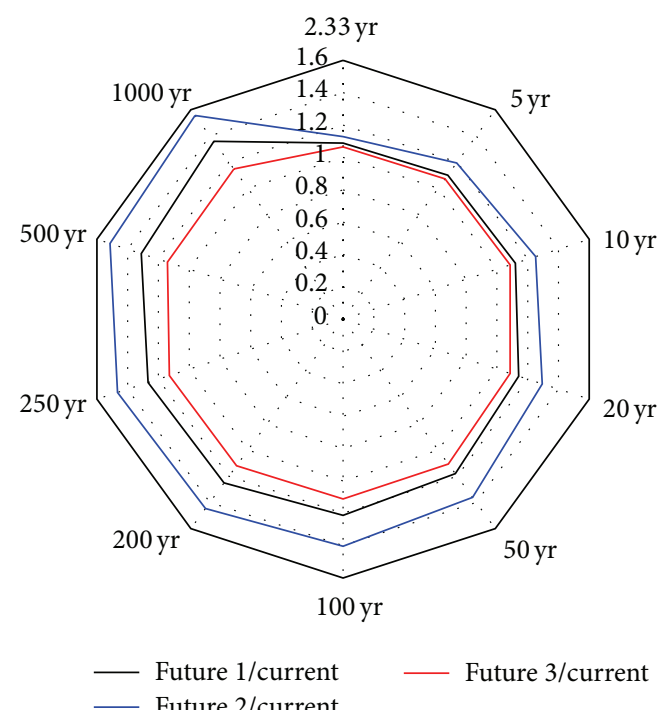

(c) Gyeongsangnam-do
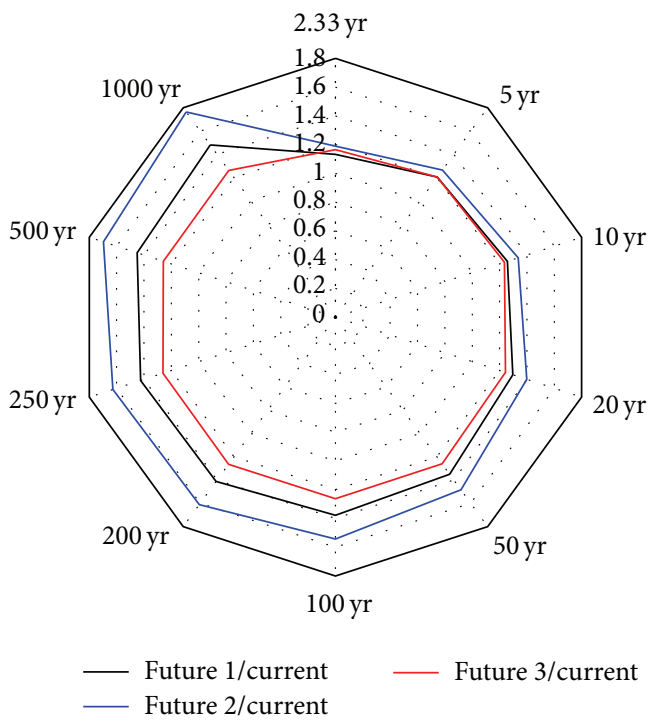

(e) Jeollanam-do

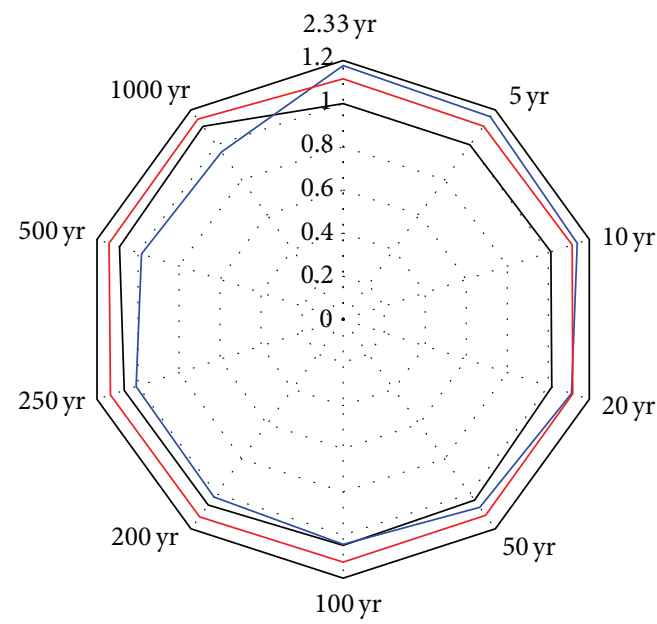

- Future 1/current — Future 3/current

(b) Gyeonggi-do

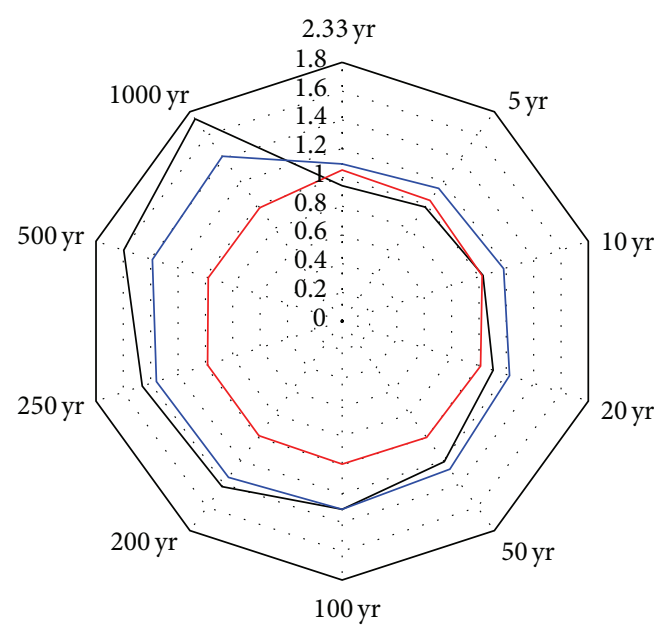

- Future 1/current — Future 3/current (d) Gyeongsangbuk-do

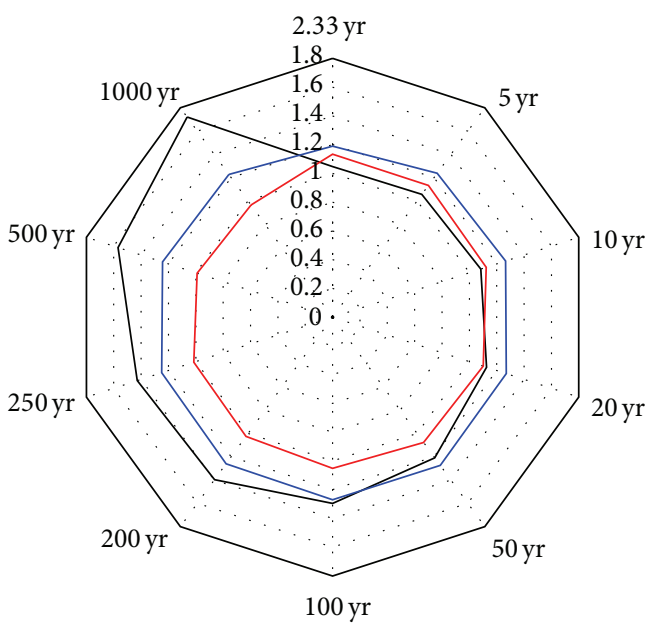

— Future 1/current — Future 3/current

(f) Jeollabuk-do

FIGURE 9: Continued. 


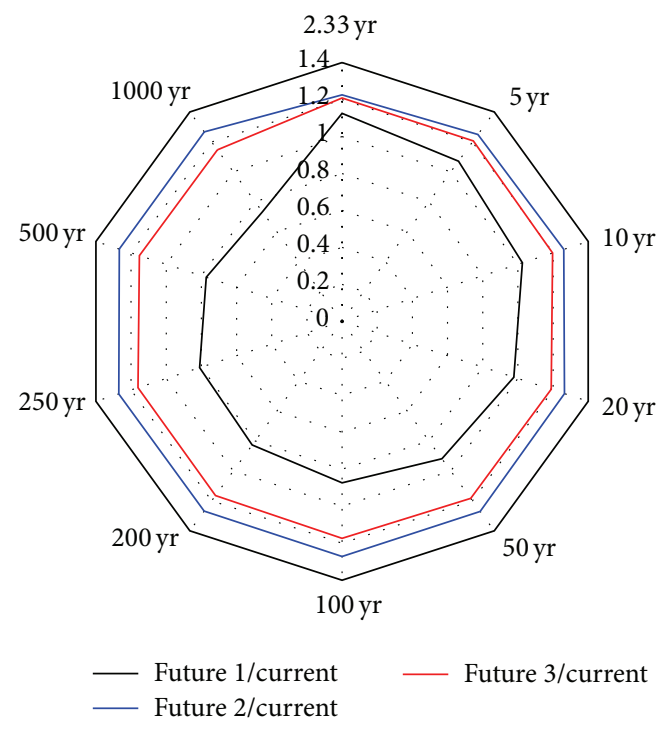

(g) Chungcheongnam-do

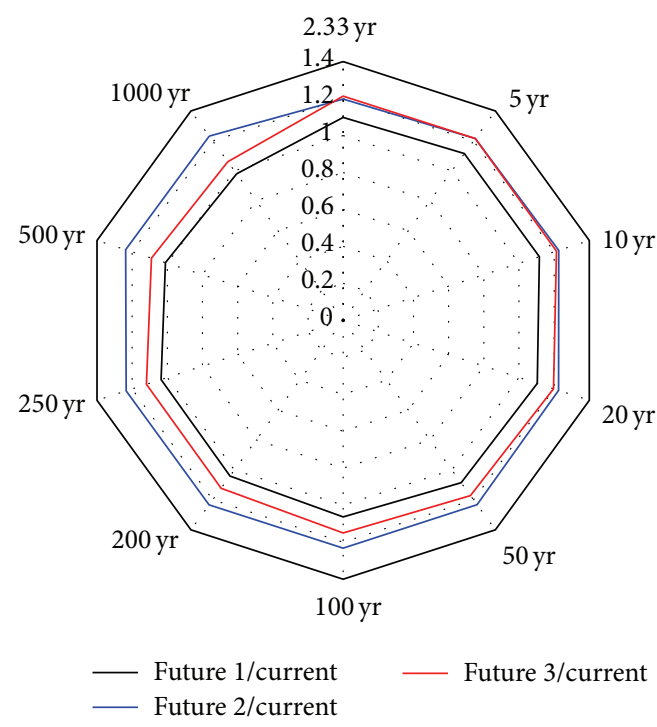

(h) Chungcheongbuk-do

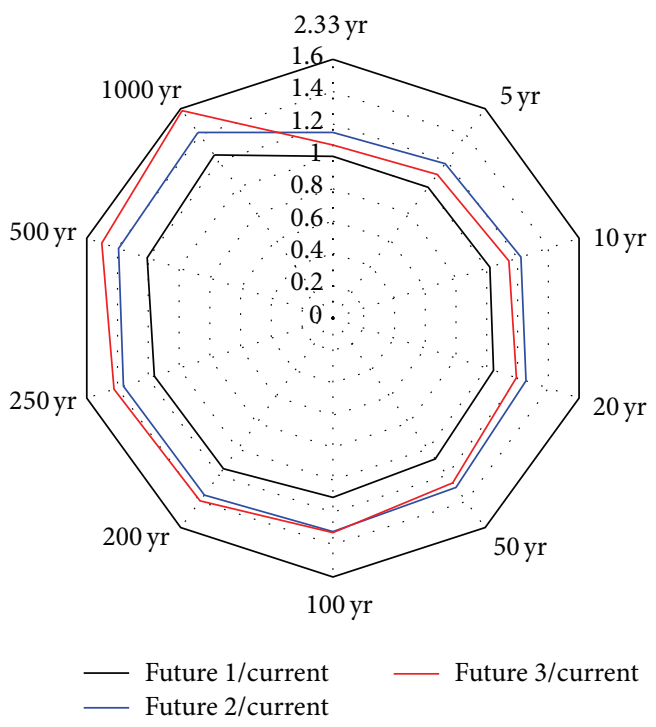

(i) Jeju

FIGURE 9: Ratio of drought magnitude in the future climate to the current climate.

was becoming increasingly larger in the future (Figure 10). However, the total drought in Gangwon-do, Gyeonggi-do, Jeollanam-do, Chungcheongbuk-do, and Jeju-do was larger in the middle part than the later part of the 21st century. The extreme total drought below " -1.5 " also showed the trend of becoming increasingly larger in the future; however, the total drought in Gangwon-do, Gyeonggi-do, and Jeju-do was larger in the middle part than the later part of the 21st century, and the total drought in Jeollanam-do Province remained in a similar level from the first part to the later part of the 21st century.

The maximum drought intensity below "-1" of the SPEI was becoming stronger and stronger in the future (Figure 11). However, the maximum drought intensity in Gangwondo, Gyeonggi-do, Gyeongsangnam-do, Jeollanam-do,
Jeollabuk-do, Chungcheongbuk-do, and Chungcheongnamdo was stronger in the middle part than the later part of the 21 st century. The maximum drought intensity below " -1.5 " also showed the trend of becoming increasingly stronger in the future, but the maximum drought intensity in Gangwondo, Gyeonggi-do, Gyeongsangnam-do, Jeollanam-do, and Jeju-do was projected to be stronger in the middle part than the later part of the 21st century.

The drought magnitude below " -1 " of the SPEI was becoming increasingly larger in the future even though the extent is comparatively less than the total drought and maximum drought intensity (Figure 12). However, it was projected that the drought magnitude of similar magnitude will continue from the current climate to the first part of the 21st century in Gangwon-do, Gyeonggi-do, 


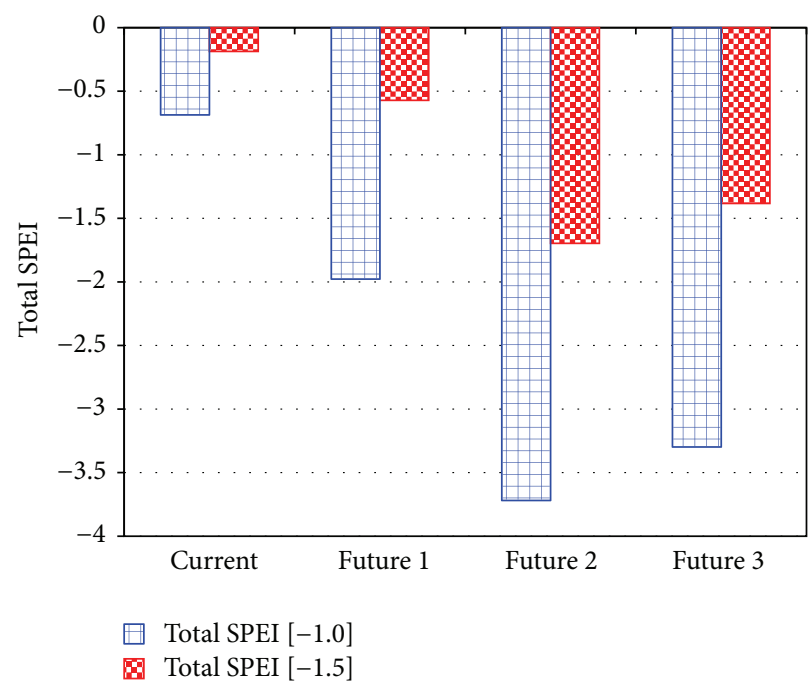

(a) Gangwon-do

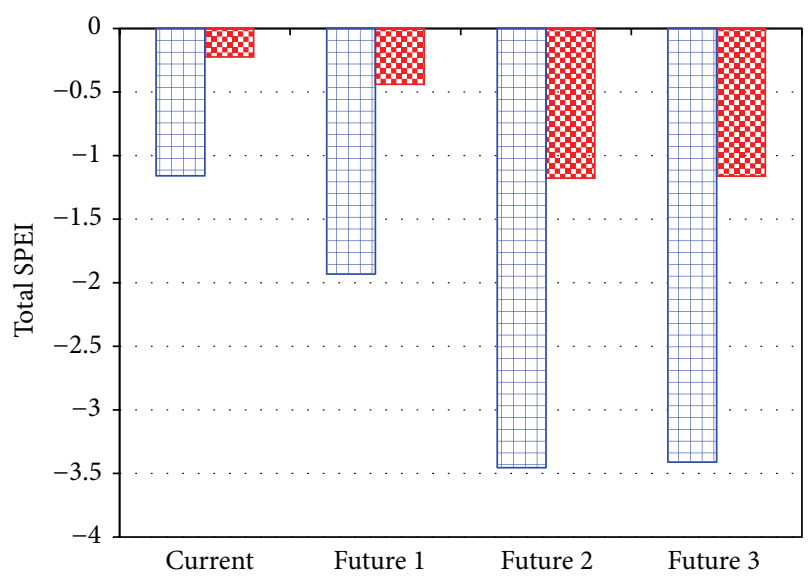

$\square$ Total SPEI [-1.0]

(7) Total SPEI $[-1.5]$

(c) Gyeongsangnam-do

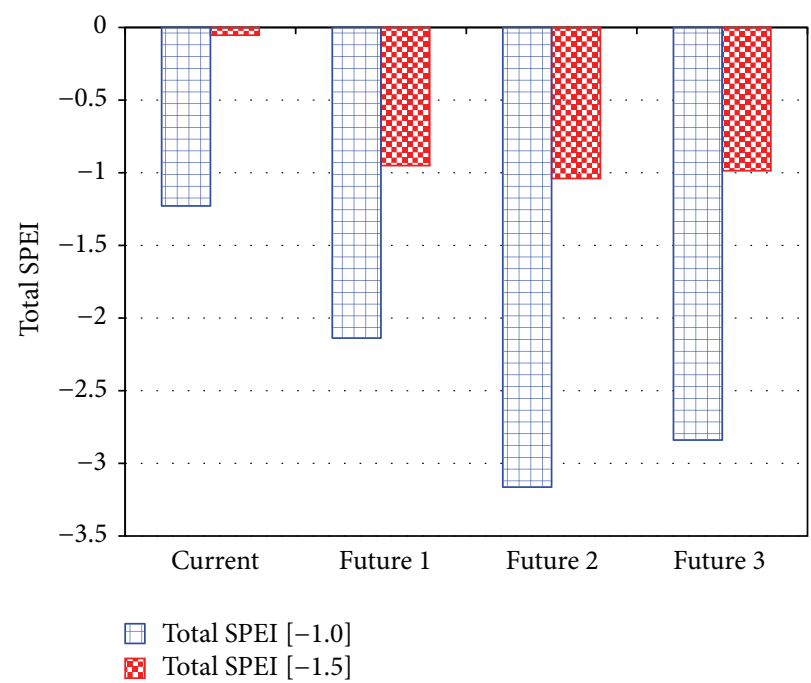

(e) Jeollanam-do

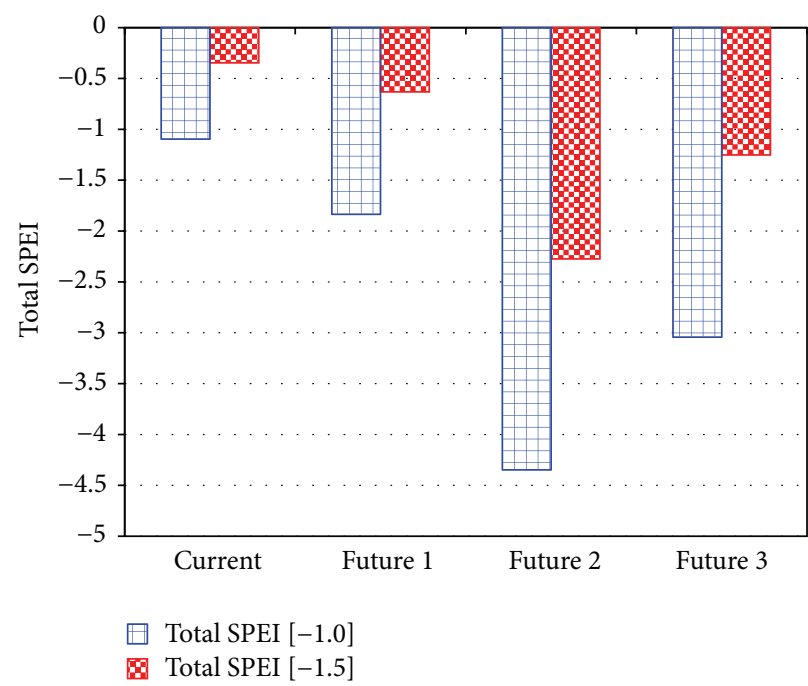

(b) Gyeonggi-do

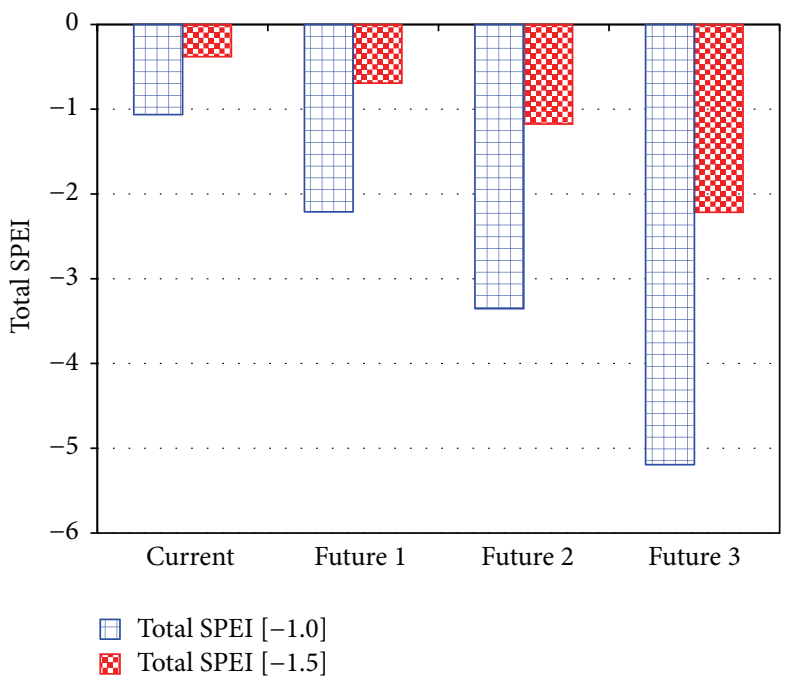

(d) Gyeongsangbuk-do

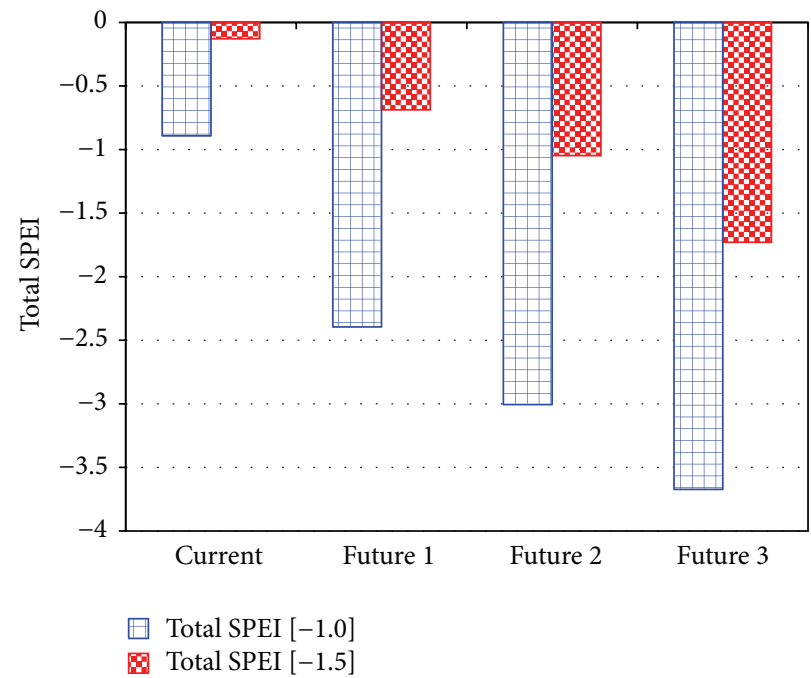

(f) Jeollabuk-do

Figure 10: Continued. 


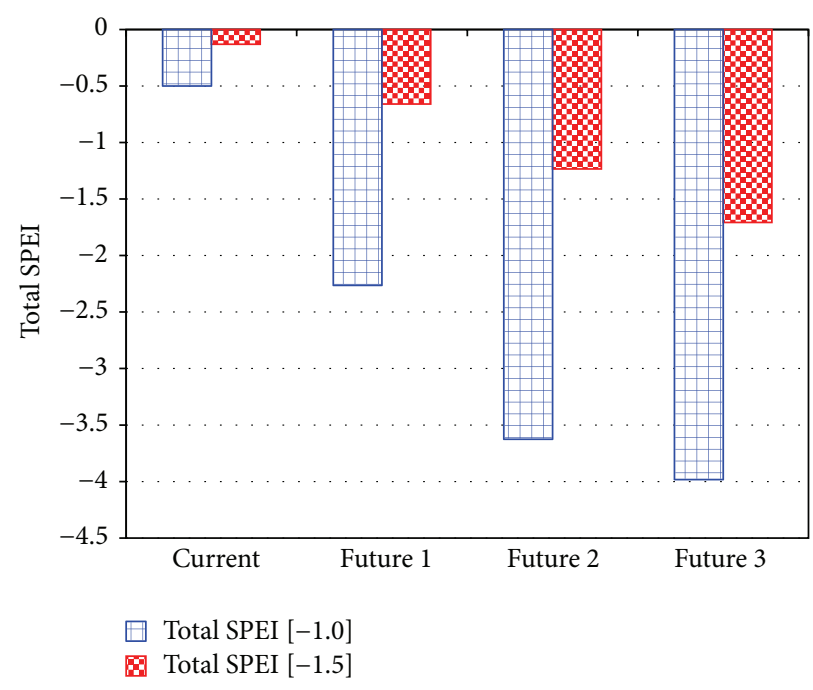

(g) Chungcheongnam-do

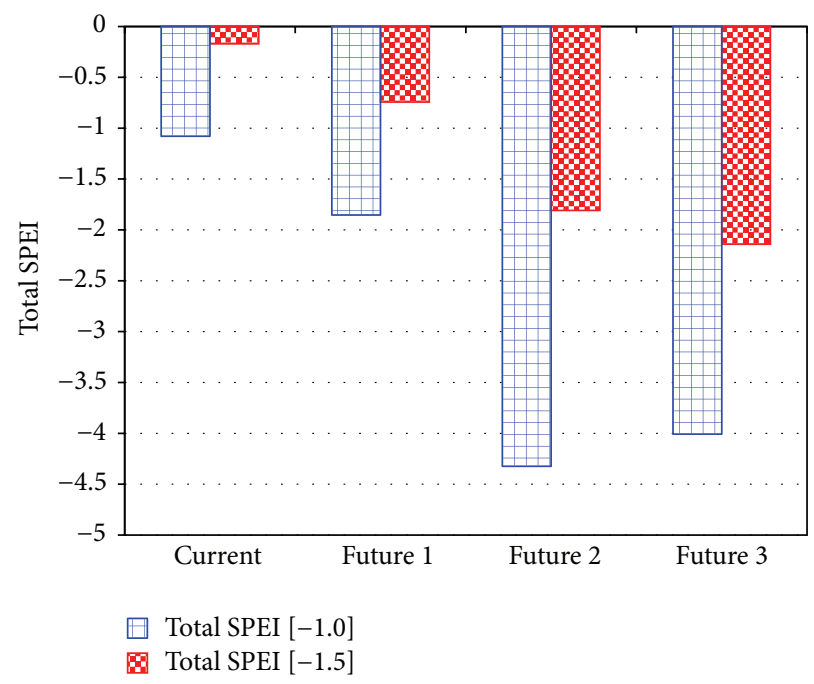

(h) Chungcheongbuk-do

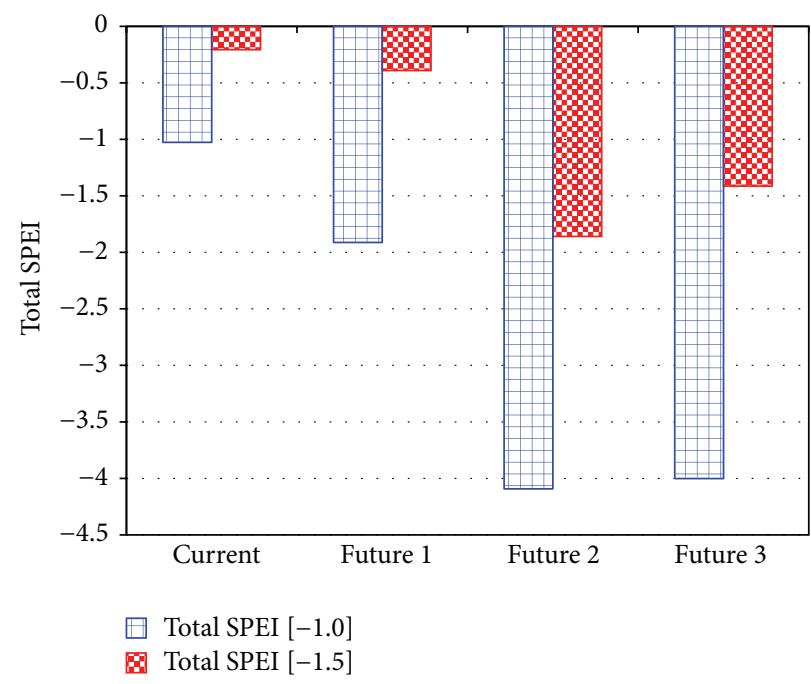

(i) Jeju

FIGURE 10: Change in total drought in the current and future climates.

and Jeollanam-do and that the drought magnitude in Gangwon-do, Gyeonggi-do, Gyeongsangnam-do, Jeollanamdo, Jeollabuk-do, Chungcheongnam-do, Chungcheongbukdo, and Jeollabuk-do was projected to become larger in the middle part than the later part of the 21st century. The drought magnitude below "1.5" also showed the trend of becoming increasingly larger in the future; however, the drought magnitude in Gangwon-do, Gyeonggi-do, Gyeongsangnam-do, and Jeju-do was projected to become larger in the middle part than the later part of the 21st century.

The drought duration in each drought period was calculated (Figure 13). The drought duration below “-1" was 0.76 months/year in the current climate, but drought duration was projected to become increasingly longer in the future and extreme drought to last for longer than 2.50 months/year (Figure 12). The calculation of the drought duration below "1.5" showed similar results. The drought duration was
0.13 months/year in the current climate, but the drought duration was projected to become increasingly longer in the future and extreme drought to last for longer than 1.10 months/year (Figure 12). In general, in Gyeongsangbuk-do Province, the drought below " -1 " is expected to last for longer than three months in the later part of the 21st century and the severer drought below " -1.5 " is expected to last for about two months. In Chungcheongbuk-do Province, it was projected that the drought below " -1 ” will last for about three months in the middle part of the 21st century, but with the duration expected to decrease in the later part of the 21st century.

\section{Conclusions}

This study aimed to identify the drought characteristics by applying the threshold level method and projected 


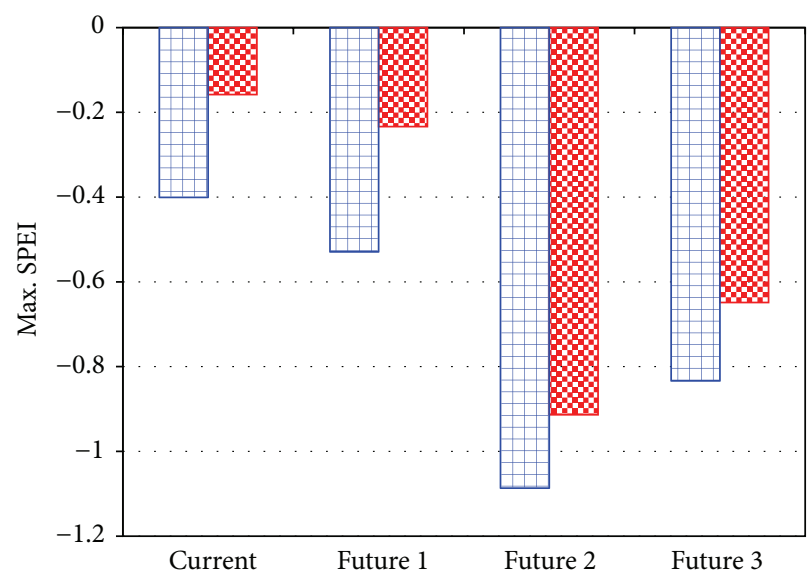

$\square$ Max. SPEI $[-1.0]$

용 Max. SPEI [-1.5]

(a) Gangwon-do

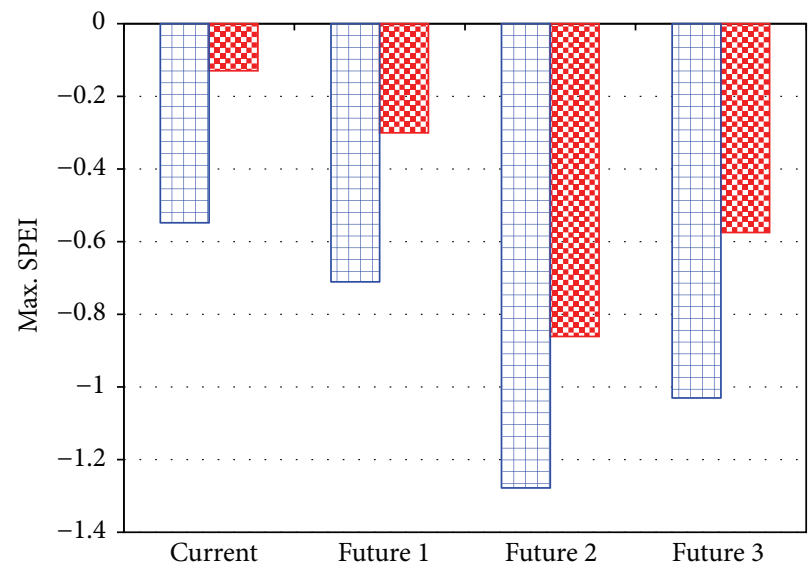

$\square$ Max. SPEI $[-1.0]$

月 Max. SPEI [-1.5]

(c) Gyeongsangnam-do

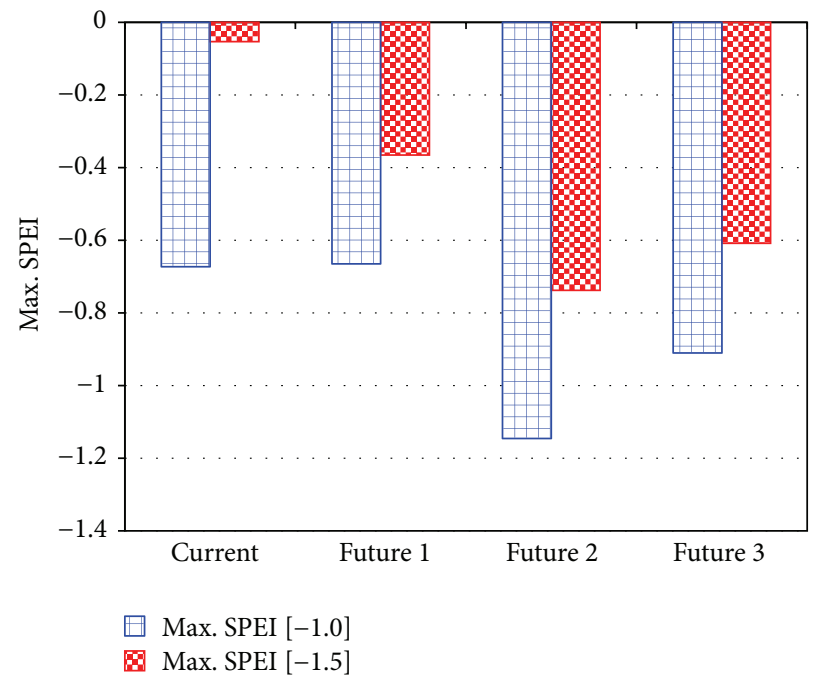

(e) Jeollanam-do

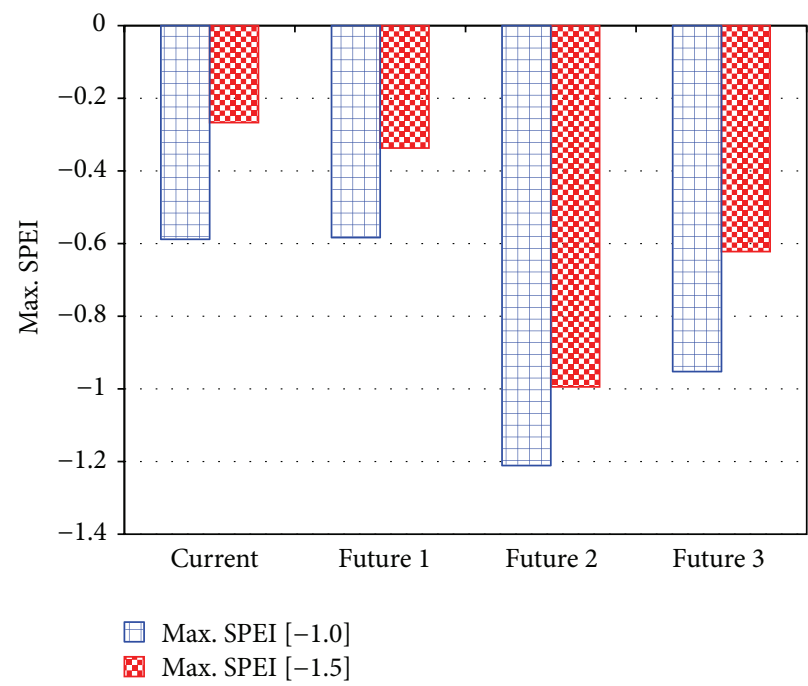

(b) Gyeonggi-do

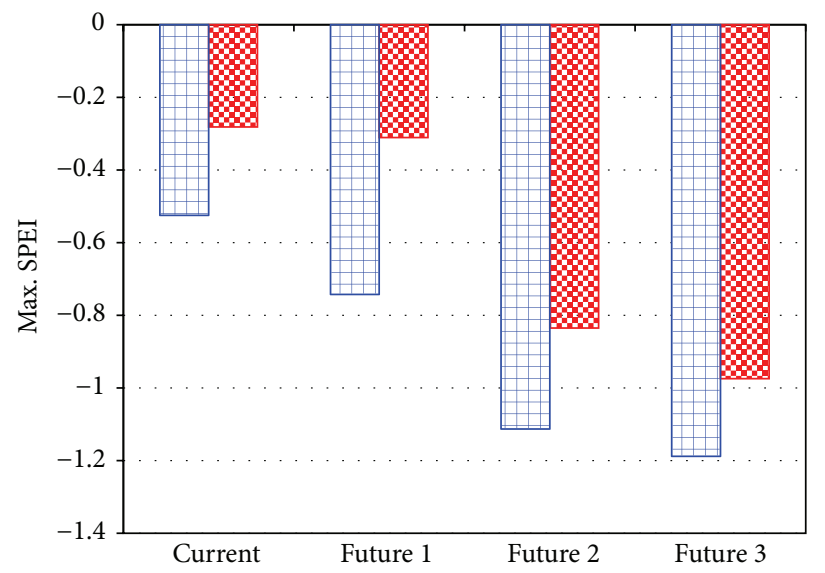

$\square$ Max. SPEI $[-1.0]$

웅 Max. SPEI $[-1.5]$

(d) Gyeongsangbuk-do

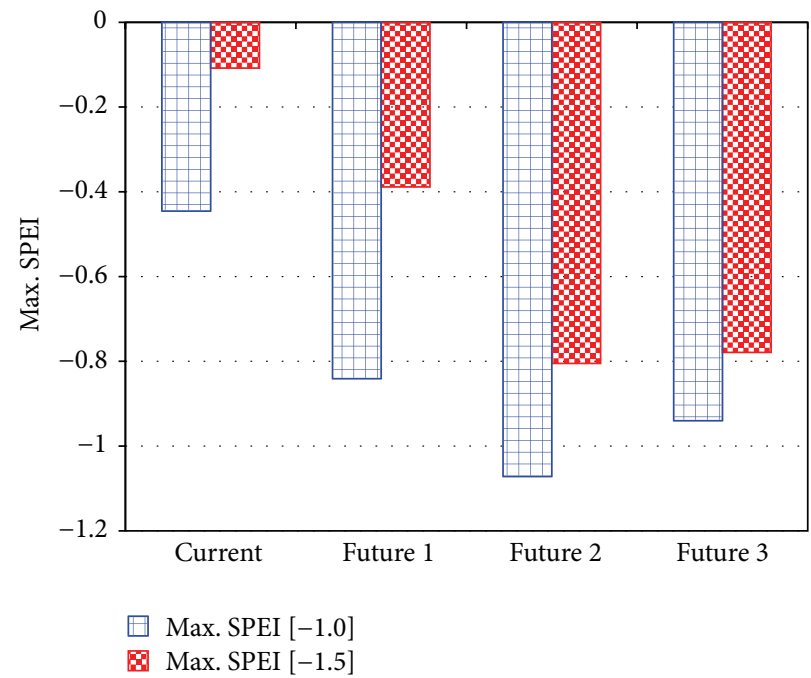

(f) Jeollabuk-do

FIgURE 11: Continued. 


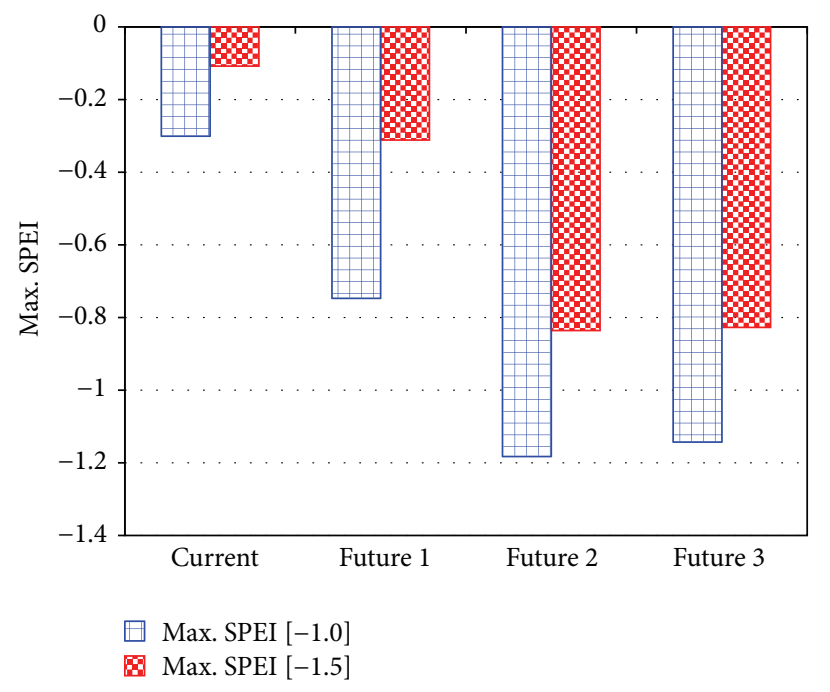

(g) Chungcheongnam-do

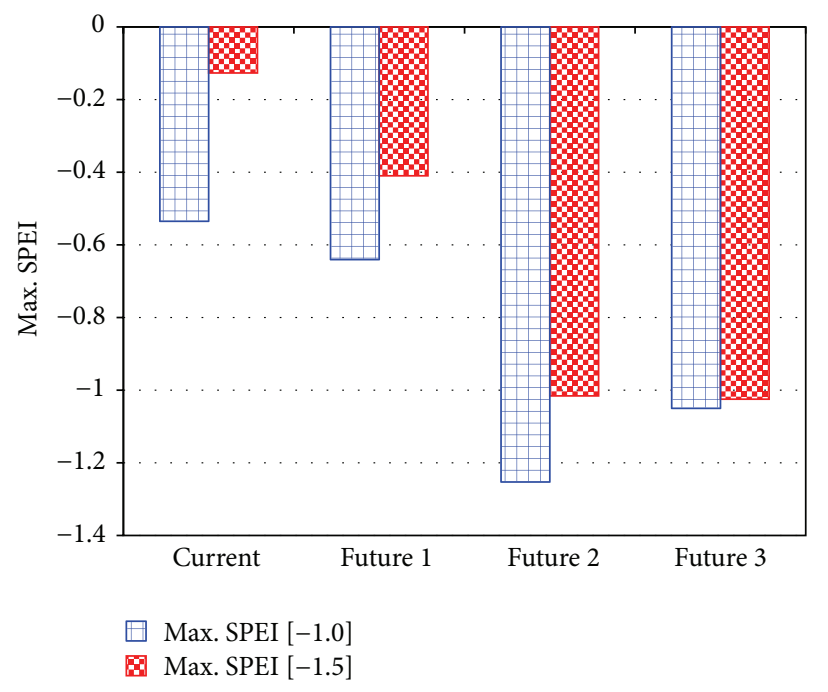

(h) Chungcheongbuk-do

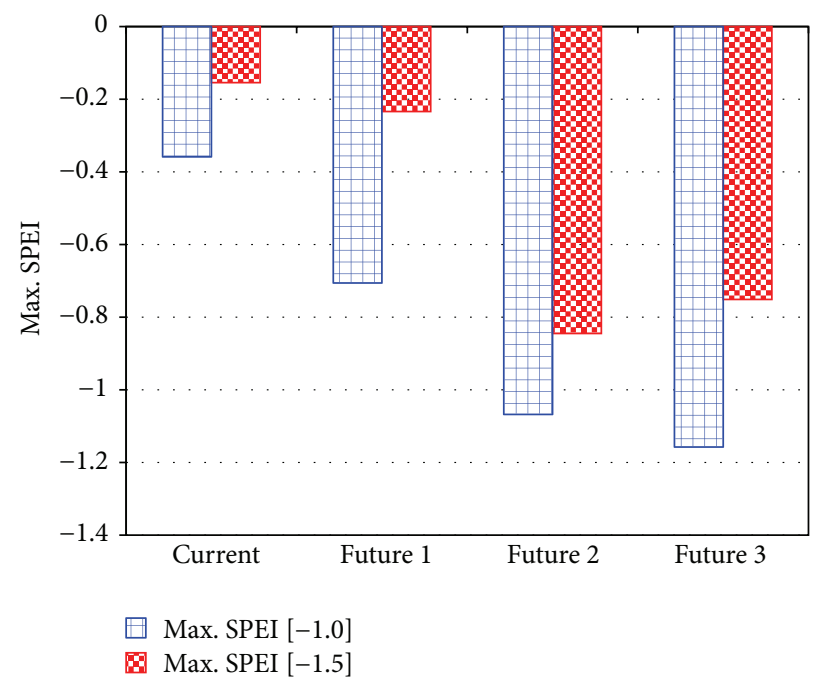

(i) Jeju

FIgURE 11: Change in maximum drought intensity in the current and future climates.

the drought risk of each administrative division in South Korea in the 21st century by fitting the identified drought characteristics to GEV distribution. The result of the analysis about the total drought, maximum drought intensity, and drought magnitude showed that the PDF of the total drought and maximum drought intensity was moving further and further to the upper tail part, and the drought of stronger intensity was also projected to occur more frequently in the future than the current in the right side of the GEV distribution.

The total volume of the mild drought was projected to increase from the current $0.97 /$ year to $3.72 /$ year in the later part of the 21st century, and the total volume of the severe drought was projected to increase from the current 0.20 /year to 1.55 /year in the later part of the 21 st century. The maximum drought intensity of the mild drought was projected to increase from the current 0.49 /year to 1.02 /year in the later part of the 21st century, and the maximum drought intensity of the severe drought was projected to increase from the current 0.15 /year to 0.76 /year in the later part of the 21st century. The average drought intensity of the mild drought was projected to increase from the current $0.45 /$ year to $0.87 /$ year in the later part of the 21 st century, and the average drought intensity of the severe drought was projected to increase from the current 0.14 /year to 0.65 /year in the later part of the 21st century. As a result of drought duration calculation, the duration of the mild drought was 0.76 months/year in the current climate, but it was projected to become increasingly longer in the future and to last for longer than 2.50 months/year in the future climate. As a result of calculating severe drought duration, the drought duration was 0.13 months/year in the current climate, but it 


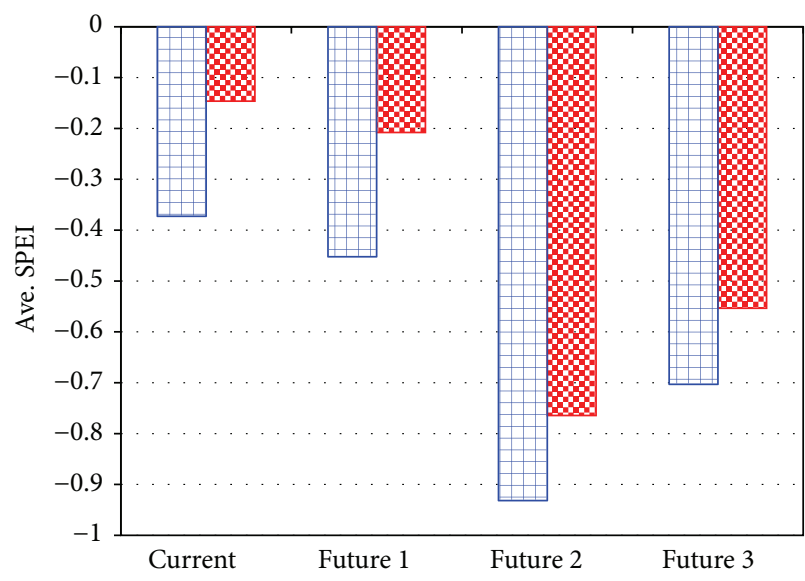

$\square$ Ave. SPEI $[-1.0]$

Ave. SPEI [-1.5]

(a) Gangwon-do

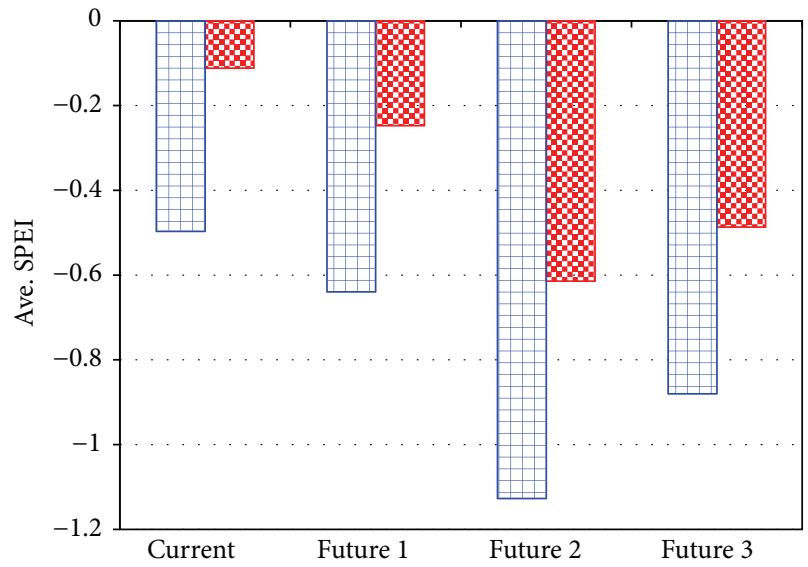

$\square$ Ave. SPEI $[-1.0]$

용 Ave. SPEI $[-1.5]$

(c) Gyeongsangnam-do

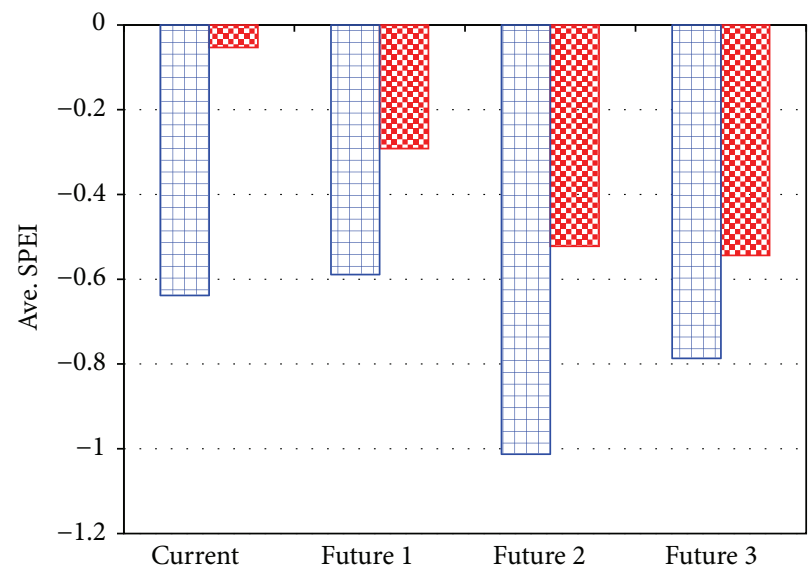

$\square$ Ave. SPEI $[-1.0]$

Ave. SPEI $[-1.5]$

(e) Jeollanam-do

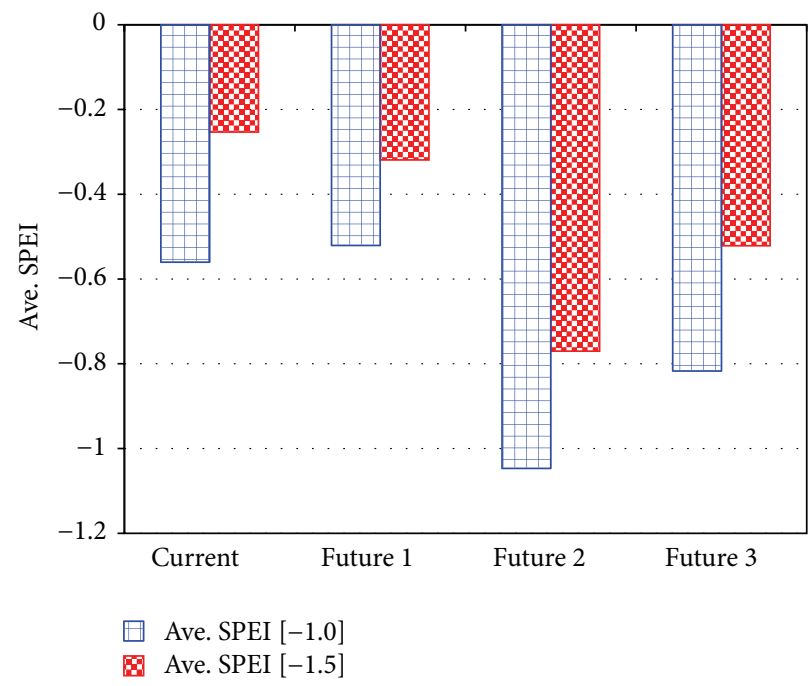

(b) Gyeonggi-do

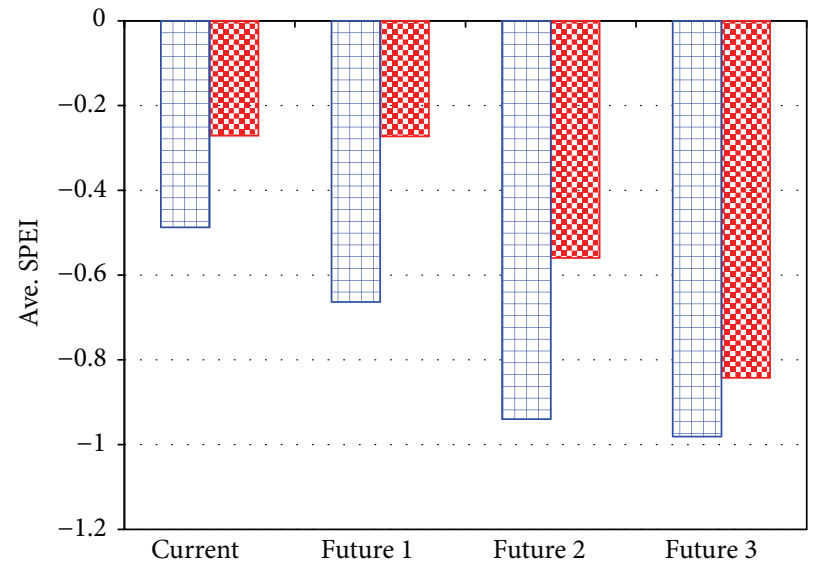

$\square$ Ave. SPEI $[-1.0]$

용 Ave. SPEI [-1.5]

(d) Gyeongsangbuk-do

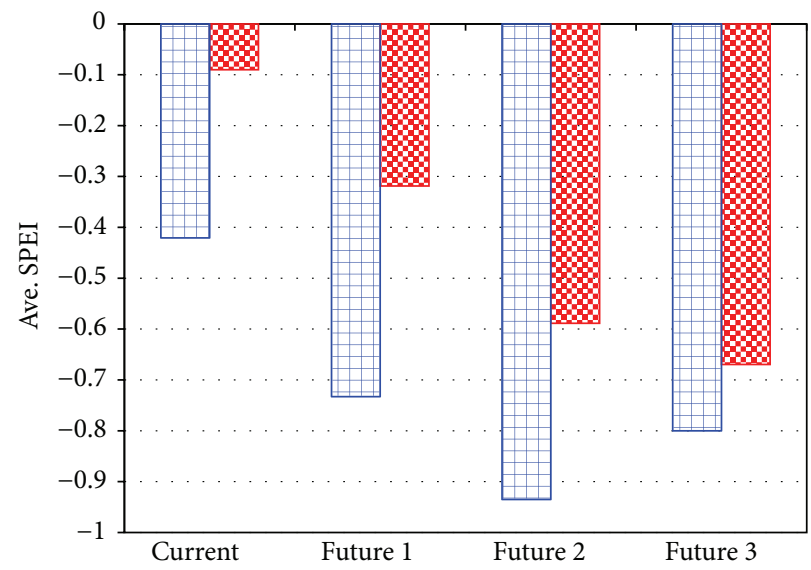

$\square$ Ave. SPEI [-1.0]

Ave. SPEI $[-1.5]$

(f) Jeollabuk-do

Figure 12: Continued. 


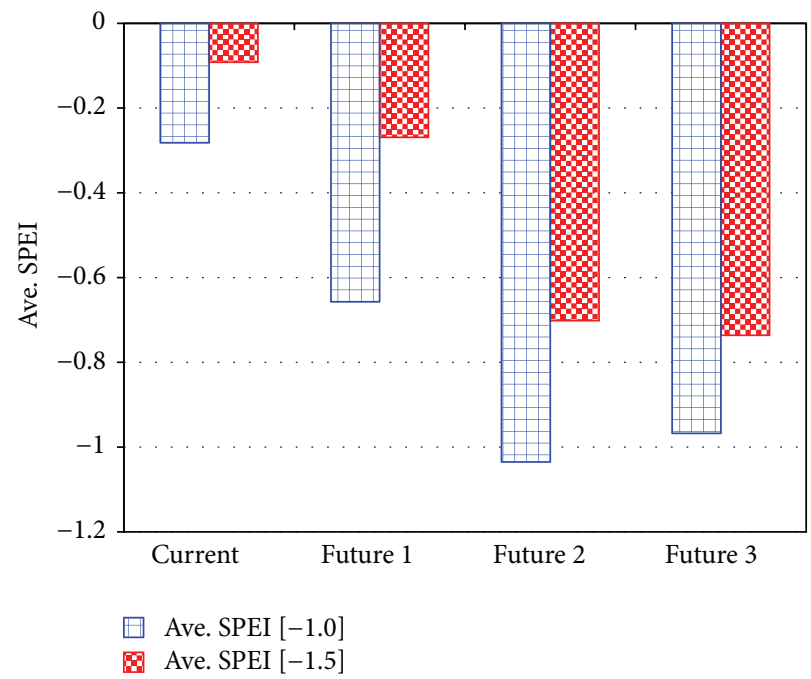

(g) Chungcheongnam-do

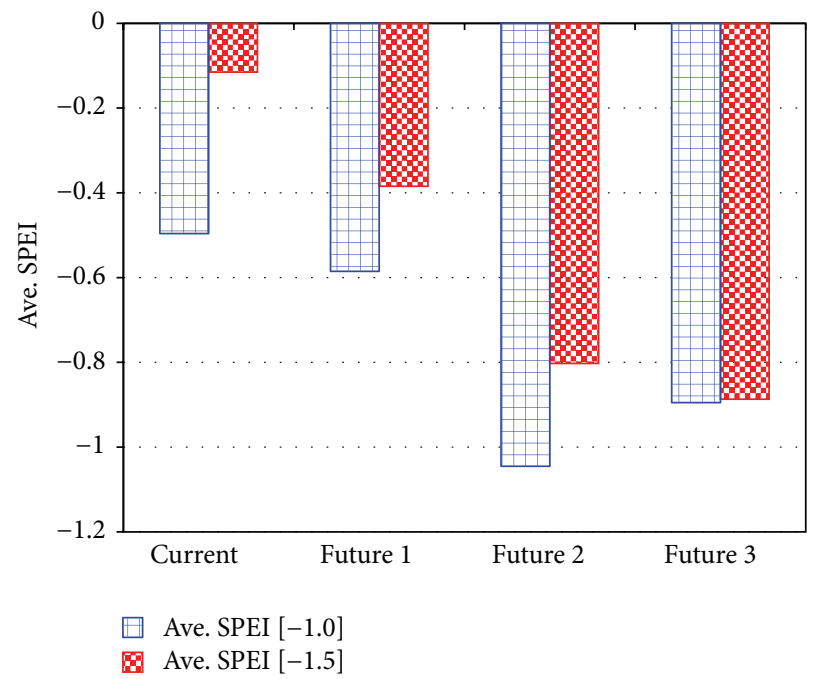

(h) Chungcheongbuk-do

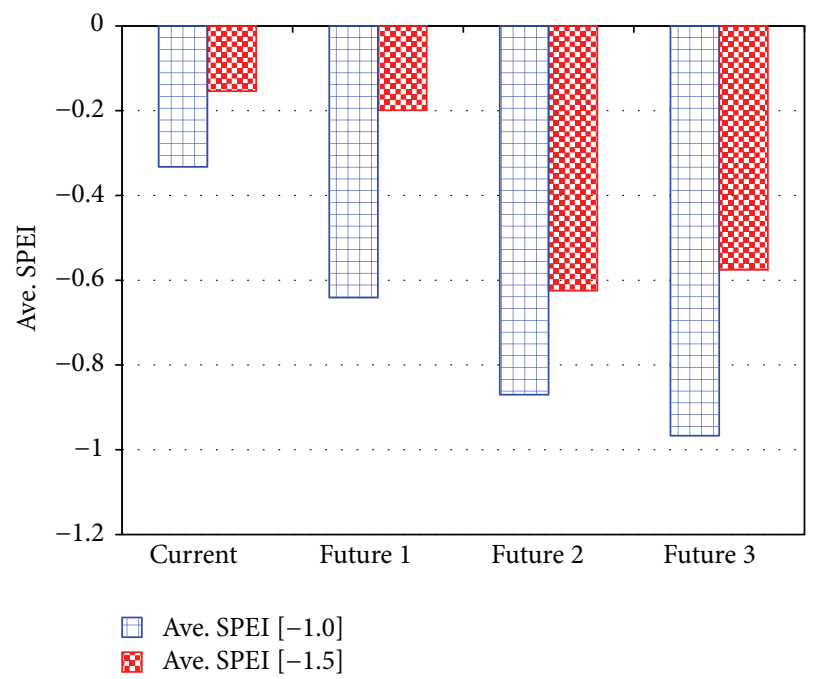

(i) Jeju

FIGURE 12: Change in drought magnitude in the current and future climates.

was projected to become increasingly longer in the future and to last for longer than 1.10 months/year in the future climate.

Drought magnitude and duration are key variables. With this, according to the extent of human needs, the drought magnitude also needs to take into consideration separately the maximum drought intensity, drought magnitude, and total drought. In the health-welfare area, for example, the maximum drought intensity among drought features will be the most useful in preventing drought damage (high temperature and dryness) to people belonging to the vulnerable class, and the drought magnitudewith the same concept as precipitation intensity-can provide useful information to the designers of water supply facilities. Because the total drought includes the concept of drought duration, it can provide useful information during the process of drought transition from agricultural to hydrological and socioeconomic drought. There is a significance in projecting future drought on the basis of the extreme climate. Because this study has a limitation to employ a single scenario, future studies should attempt to quantify uncertainties in the combination of multiple scenarios.

\section{Conflict of Interests}

The authors declare that there is no conflict of interests regarding the publication of this paper. 


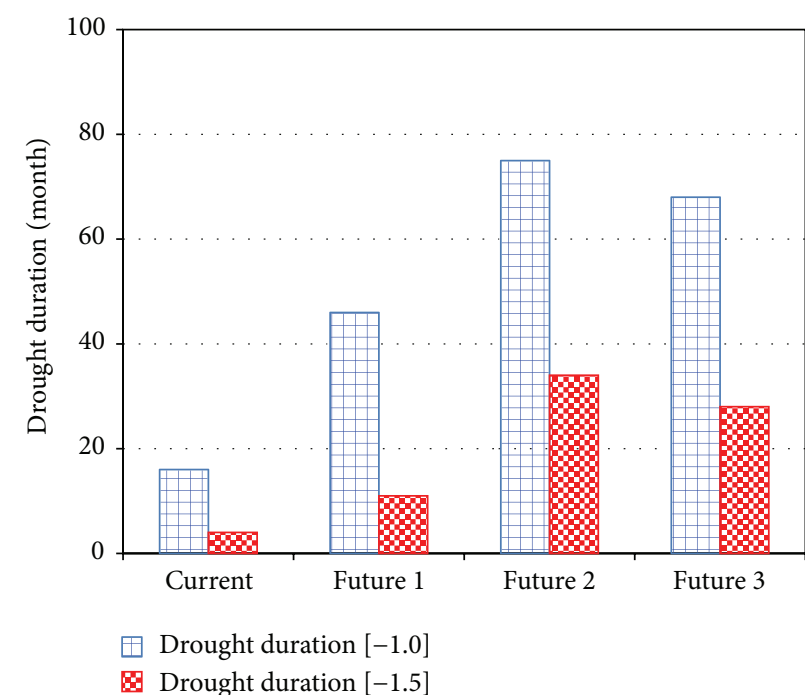

(a) Gangwon-do

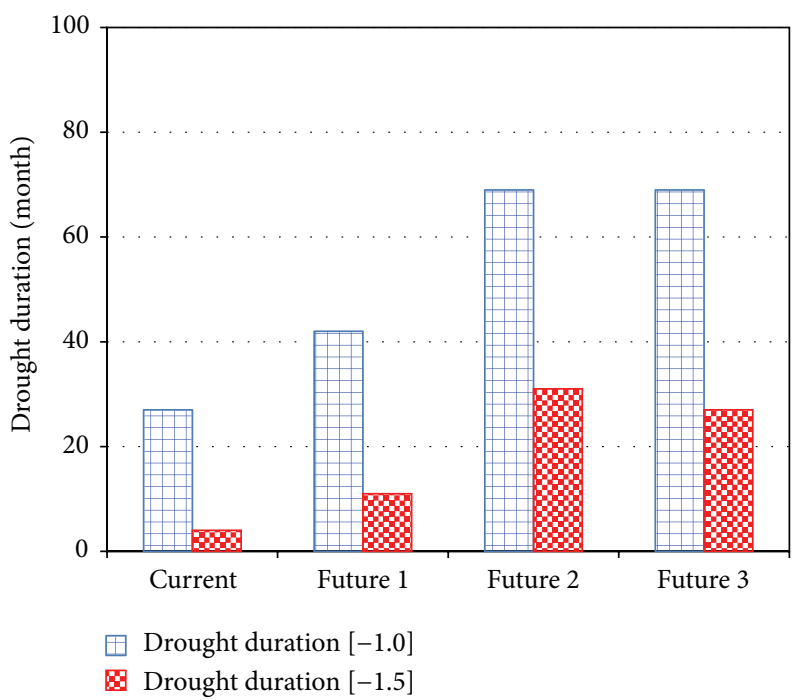

(c) Gyeongsangnam-do

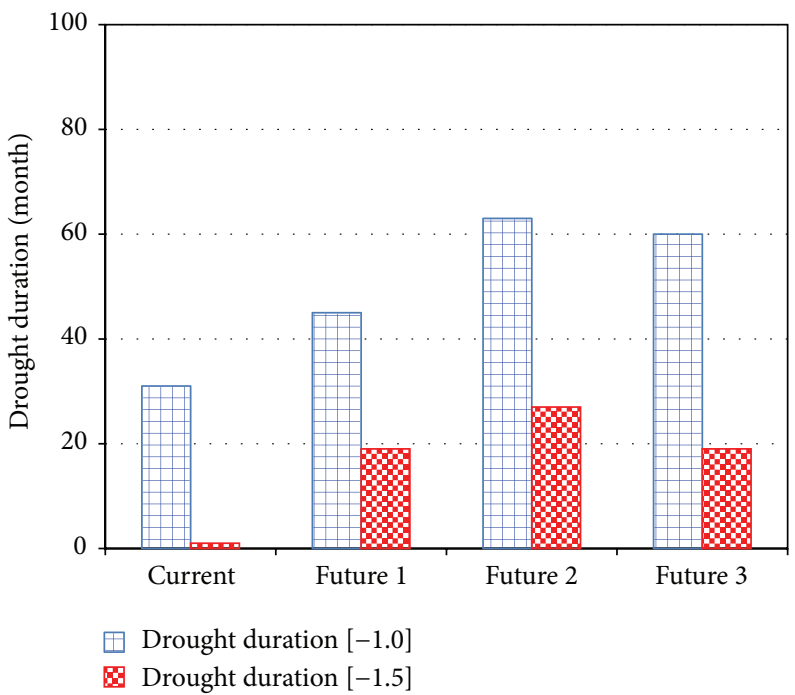

(e) Jeollanam-do

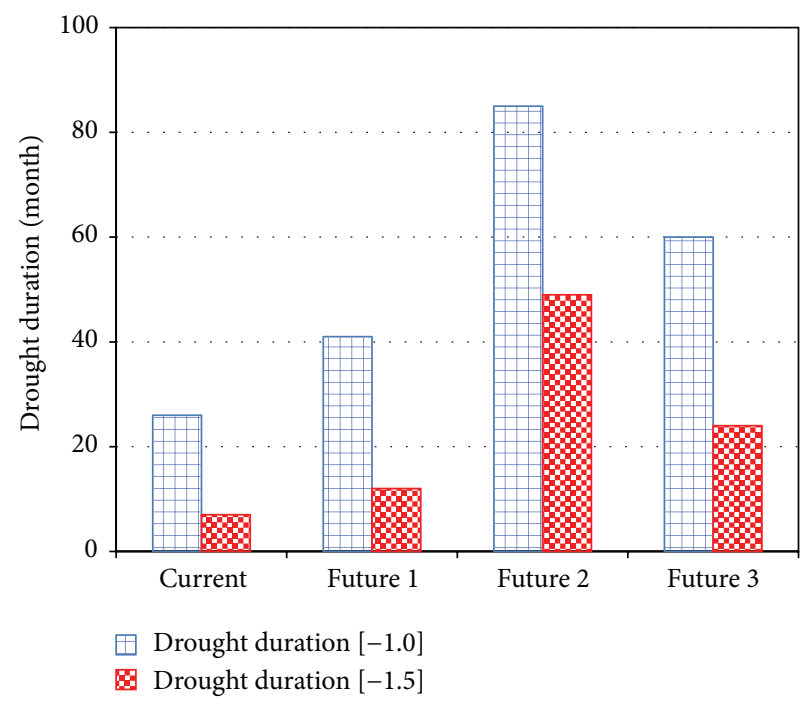

(b) Gyeonggi-do

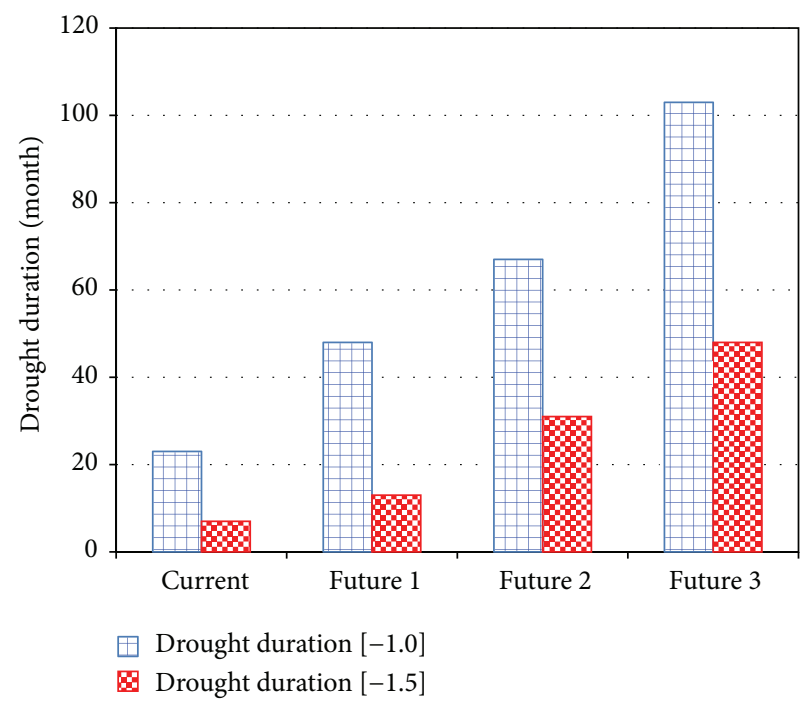

(d) Gyeongsangbuk-do

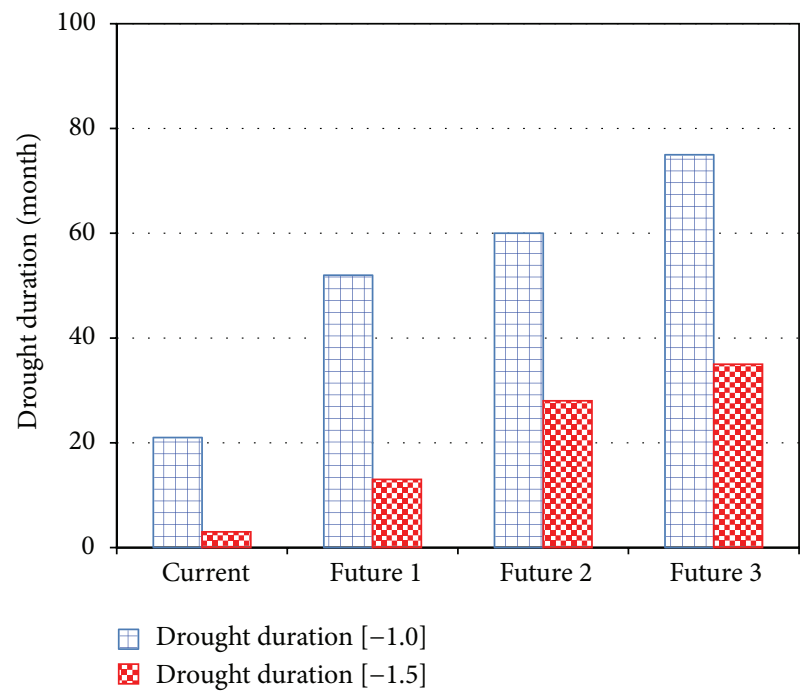

(f) Jeollabuk-do

Figure 13: Continued. 


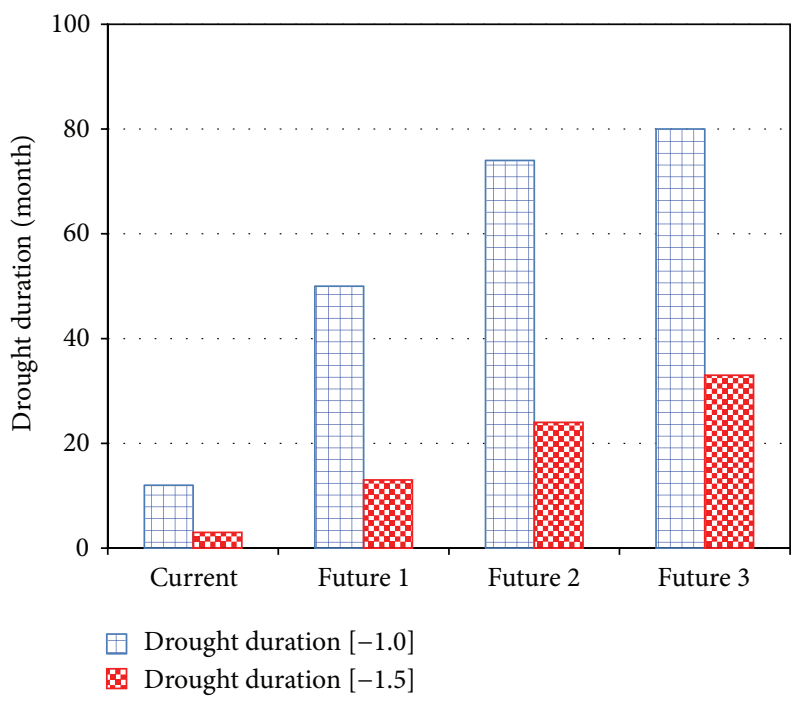

(g) Chungcheongnam-do

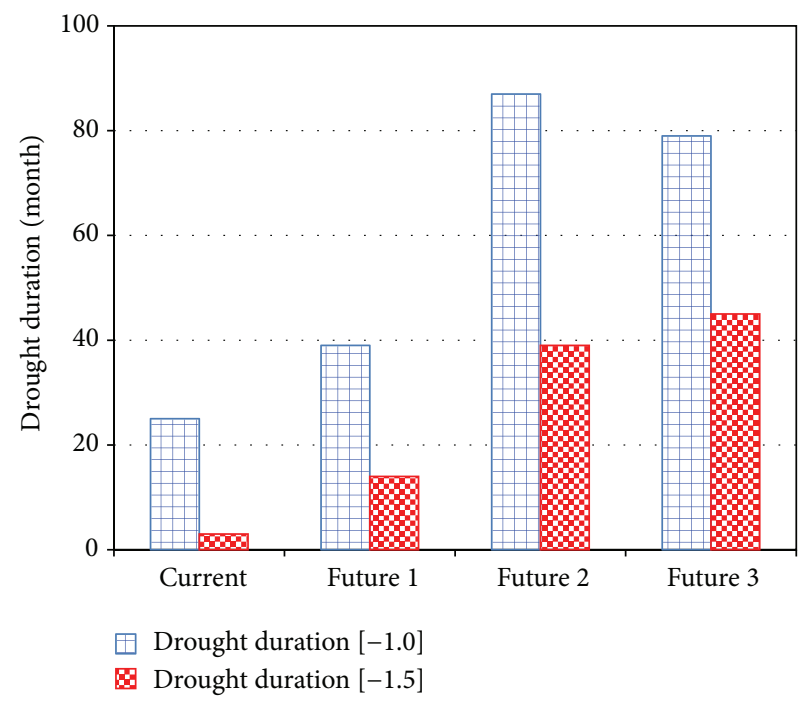

(h) Chungcheongbuk-do

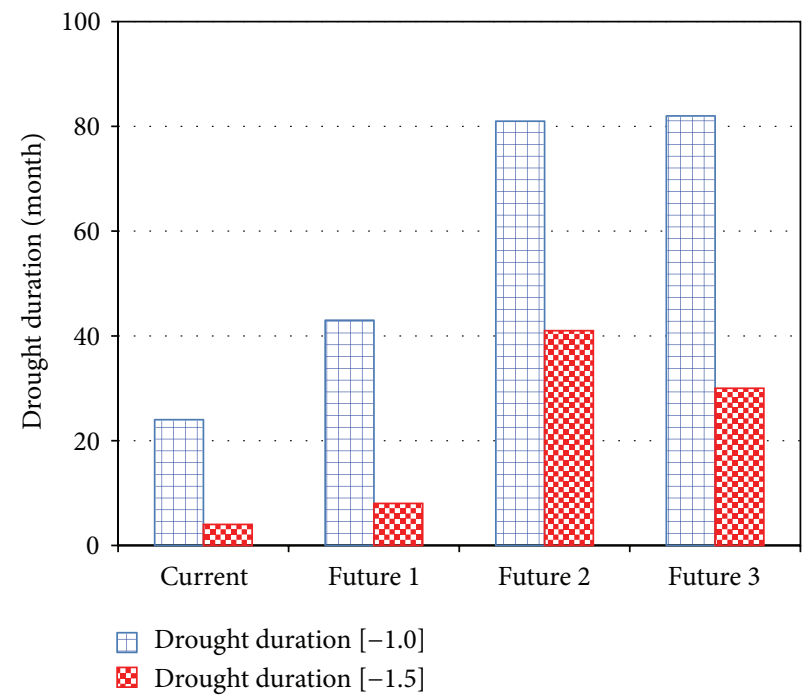

(i) Jeju

FIGURE 13: Change in drought duration in the current and future climates.

\section{Acknowledgment}

This study was supported by the 2011 Research Grant from Kangwon National University.

\section{References}

[1] B. S. Kim, H. S. Kim, B. H. Seoh, and N. W. Kim, "Impact of climate change on water resources in Yongdam Dam Basin, Korea," Stochastic Environmental Research and Risk Assessment, vol. 21, no. 4, pp. 355-373, 2007.

[2] B.-S. Kim, B.-K. Kim, and H.-H. Kwon, "Assessment of the impact of climate change on the flow regime of the Han River basin using indicators of hydrologic alteration," Hydrological Processes, vol. 25, no. 5, pp. 691-704, 2011.

[3] D.-H. Bae, I.-W. Jung, and D. P. Lettenmaier, "Hydrologic uncertainties in climate change from IPCC AR4 GCM simulations of the Chungju Basin, Korea," Journal of Hydrology, vol. 401, no. 1-2, pp. 90-105, 2011.

[4] I. W. Jung, D. H. Bae, and B. J. Lee, "Possible change in Korean streamflow seasonality based on multi-model climate projections," Hydrological Processes, vol. 27, no. 7, pp. 1033-1045, 2013.

[5] K.-O. Boo, W.-T. Kwon, J.-H. Oh, and H.-J. Baek, "Response of global warming on regional climate change over Korea: an experiment with the MM5 model," Geophysical Research Letters, vol. 31, no. 21, Article ID L21206, 2004.

[6] K.-O. Boo, W.-T. Kwon, and H.-J. Baek, "Change of extreme events of temperature and precipitation over Korea using regional projection of future climate change," Geophysical Research Letters, vol. 33, no. 1, Article ID L01701, 2006.

[7] E.-S. Im, J.-B. Ahn, A. R. Remedio, and W.-T. Kwon, "Sensitivity of the regional climate of East/Southeast Asia to convective parameterizations in the RegCM3 modelling system. Part 1: 
focus on the Korean peninsula," International Journal of Climatology, vol. 28, no. 14, pp. 1861-1877, 2008.

[8] B. Kim, J. H. Sung, B. H. Lee, and D. J. Kim, "Evaluation on the impact of extreme droughts in South Korea using the SPEI and RCP8.5 climate change scenario," Journal of Korean Society of Hazard Mitigation, vol. 13, no. 2, pp. 97-109, 2013.

[9] D. A. Wilhite and M. H. Glantz, "Understanding the drought phenomenon: the role of definitions," Water International, vol. 10, no. 3, pp. 111-120, 1985.

[10] A. K. Mishra and V. P. Singh, "A review of drought concepts," Journal of Hydrology, vol. 391, no. 1-2, pp. 202-216, 2010.

[11] T. B. McKee, N. J. Doesken, and J. Kieist, "The relationship of drought frequency and duration to time scales," in Proceedings of the 8th Conference of Applied Climatology, pp. 179-184, American Chemical Society, Anaheim, Calif, USA, January 1993.

[12] C. J. Kim, M. J. Park, and J. H. Lee, "Analysis of climate change impacts on the spatial and frequency patterns of drought using a potential drought hazard mapping approach," International Journal of Climatology, vol. 34, no. 1, pp. 61-80, 2014.

[13] S.-K. Min, W.-T. Kwon, E.-H. Park, and Y. Choi, "Spatial and temporal comparisons of droughts over Korea with East Asia," International Journal of Climatology, vol. 23, no. 2, pp. 223-233, 2003.

[14] M. Gocic and S. Trajkovic, "Water surplus variability index as an indicator of drought," Journal of Hydrologic Engineering, vol. 20, no. 2, Article ID 04014038, 2015.

[15] D. Rajsekhar, V. P. Singh, and A. K. Mishra, "Multivariate drought index: an information theory based approach for integrated drought assessment," Journal of Hydrology, vol. 526, pp. 164-182, 2015.

[16] S. M. Vicente-Serrano, S. Beguería, and J. I. López-Moreno, "A multiscalar drought index sensitive to global warming: the standardized precipitation evapotranspiration index," Journal of Climate, vol. 23, no. 7, pp. 1696-1718, 2010.

[17] J.-H. Lee and C.-J. Kim, "Derivation of drought severityduration-frequency curves using drought frequency analysis," Journal of Korea Water Resources Association, vol. 44, no. 11, pp. 889-902, 2011 (Korean).

[18] A. K. Mishra and V. P. Singh, "Analysis of drought severityarea-frequency curves using a general circulation model and scenario uncertainty," Journal of Geophysical Research: Atmospheres, vol. 114, no. 6, Article ID D06120, 2009.

[19] C. W. Thornthwaite, "An approach toward a rational classification of climate," Geographical Review, vol. 38, no. 1, pp. 55-94, 1948.

[20] C. W. Thornthwaite and J. R. Mather, The Water Balance, vol. 8, no. 1 of Publications in Climatology, Thornthwaite \& Associates, Centerton, NJ, USA, 1955.

[21] NIMR, Report on Climate Change Scenarios for IPCC AR5, National Institute of Meteorological Research, Seoul, Republic of Korea, 2011.

[22] H. Douville, F. Chauvin, S. Planton, J.-F. Royer, D. Salas-Mélia, and S. Tyteca, "Sensitivity of the hydrological cycle to increasing amounts of greenhouse gases and aerosols," Climate Dynamics, vol. 20, no. 1, pp. 45-68, 2002.

[23] T. P. Barnett, J. C. Adam, and D. P. Lettenmaier, "Potential impacts of a warming climate on water availability in snow- dominated regions," Nature, vol. 438, no. 7066, pp. 303-309, 2005.

[24] E. J. Burke, S. J. Brown, and N. Christidis, "Modeling the recent evolution of global drought and projections for the twentyfirst century with the Hadley Centre climate model," Journal of Hydrometeorology, vol. 7, no. 5, pp. 1113-1125, 2006. 

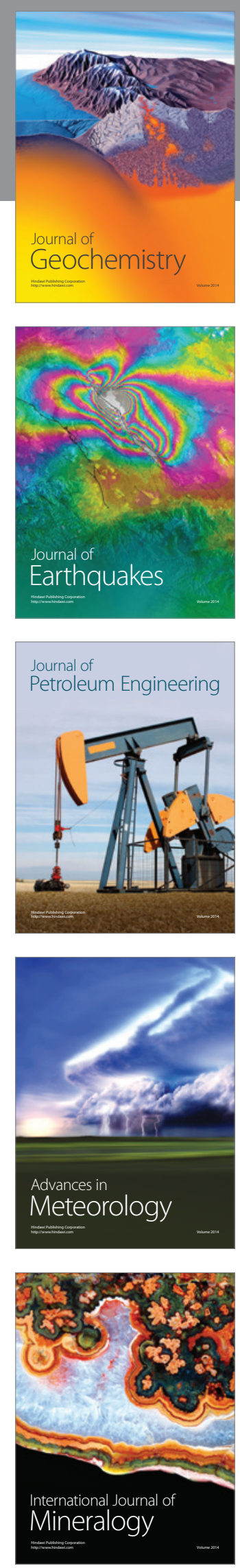
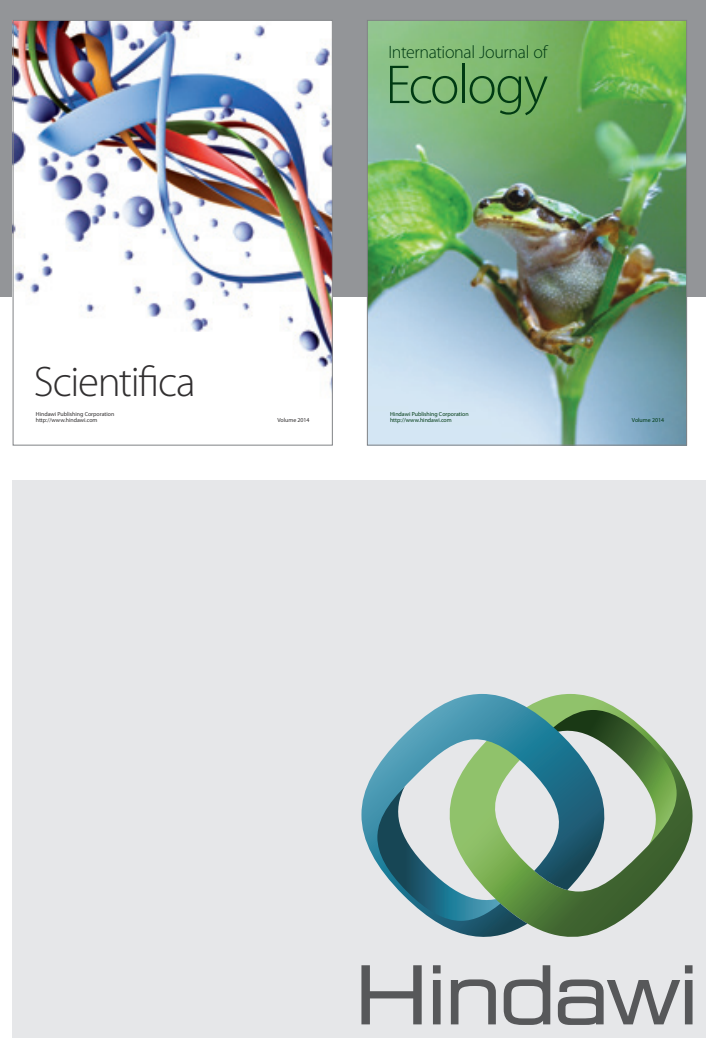

Submit your manuscripts at

http://www.hindawi.com
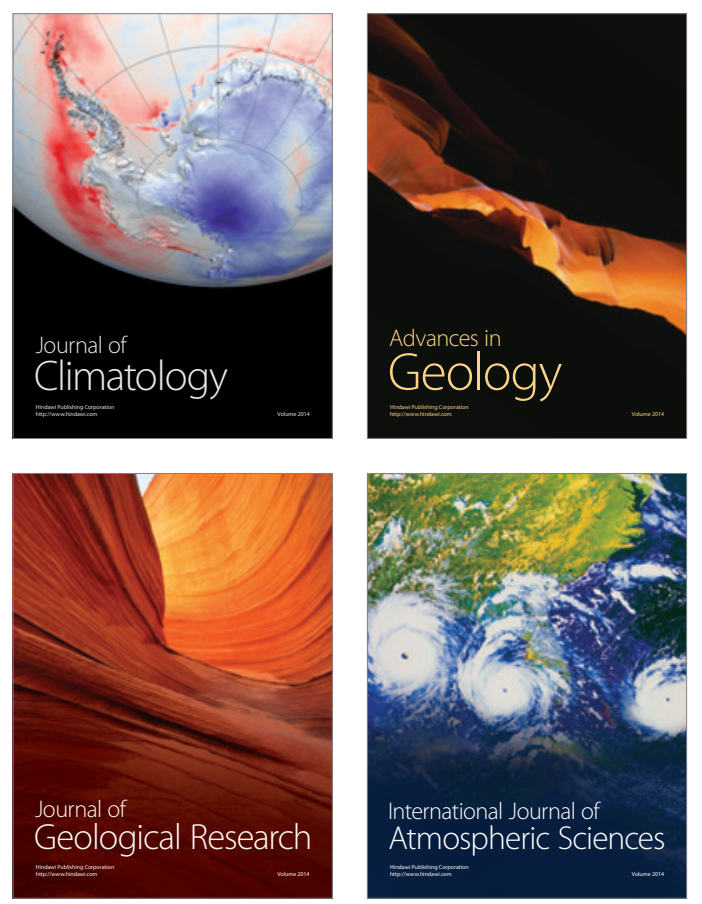

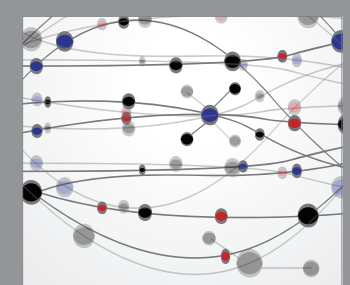

The Scientific

\section{World Journal}
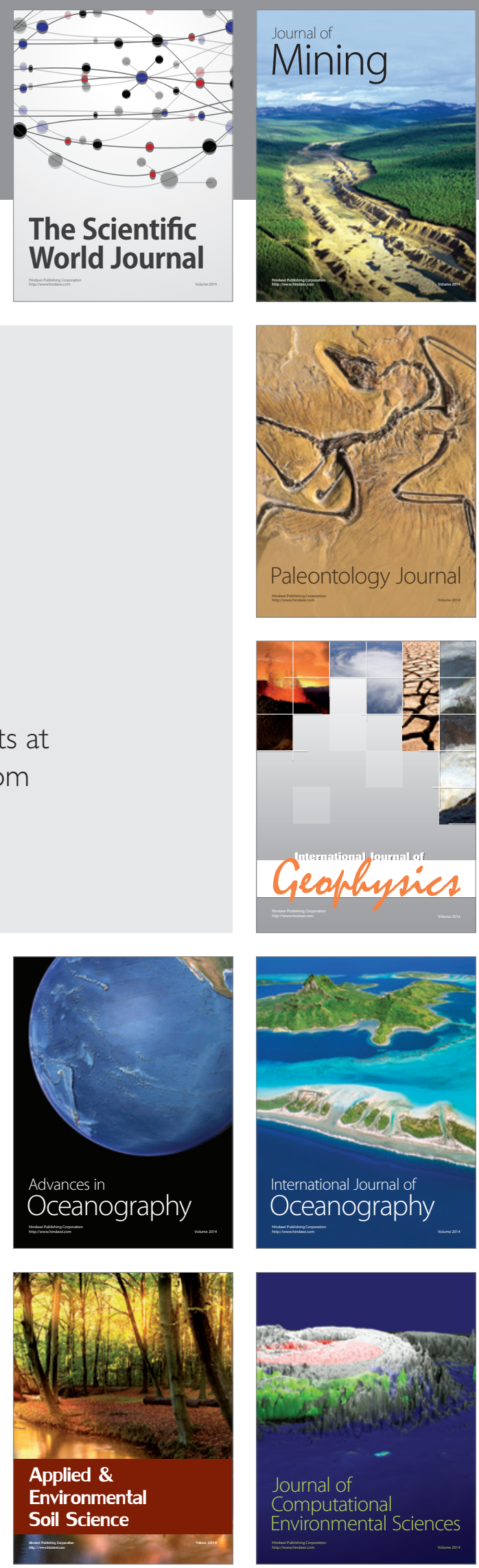